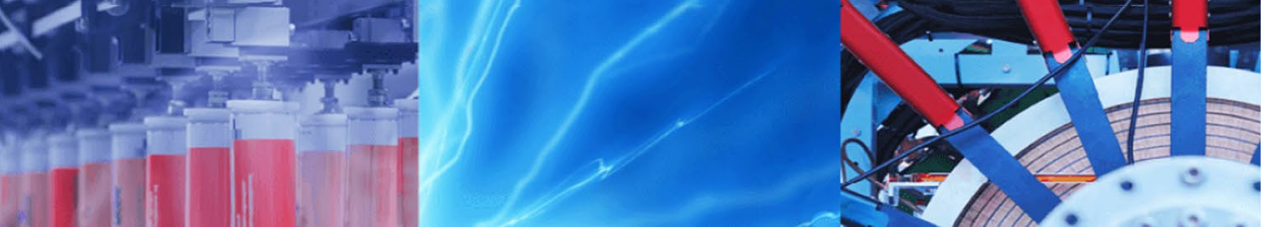

Research Article

\title{
Drainage basin morphometry and evaluating its role on flood-inducing capacity of tributary basins of Mayurakshi River, India
}

\author{
Aznarul Islam ${ }^{1}$ (D) Suman Deb Barman² ${ }^{2}$
}

Received: 27 December 2019 / Accepted: 28 April 2020 / Published online: 16 May 2020

(c) Springer Nature Switzerland AG 2020, corrected publication 2020

\begin{abstract}
The Mayurakshi River Basin (MRB), one of the most flood-prone areas of India, registers flood almost every year. The present work intends to identify the relative capacity of the tributary basins of the Mayurakshi system (three sub-basins of Dwaraka, two of Kuye and eight of Mayurakshi) to induce flood in its lower stretch. Based on basic morphometric parameters (basin length, area, perimeter, relief, stream number, and length) computed from Survey of India topographical maps $(1: 50,000)$ and SRTM DEM (30 m) using ArcGIS 10.4 software, we have derived 15 morphometric indices (linear-2, areal-7 and relief-6). The principal component analysis (PCA) depicts that there are three clusters of indices on the varimaxrotated component plot with the centroid of the distribution in positive-positive $(++)$ quadrant which signifies a peak flow. Besides, the bi-variate relations between basin lag time and different morphometric indices signal that all the variables except compactness coefficient, hypsometric integral, dissection index, and bifurcation ratio portray negative relations implying peak flow instead of sustained one. In this paper, we have developed a technique called the flood-inducing capacity index $(\mathrm{FCl})$ to measure the contribution of a tributary river to its master based on the morphometric coefficient and basin area coefficient. The $\mathrm{FCl}$ depicts that sub-basin Mayurakshi- 6 has topped the list with $\sim 21 \%$ contribution to MRB flood while Mayurakshi-8 having less than $2 \%$ contribution lies at the bottom. Besides, Dwaraka-3,Dwaraka-1 and Mayurakshi-3 basins each having more than $8 \%$ contribution control flood in the lower stretch of the Mayurakshi system. A statistically significant positive correlation $\left(R^{2}=0.75\right)$ between the maximum discharge measured for the nine sub-basins and the $\mathrm{FCl}$ and the area under curve (0.889) on ROC plot ground the validation of the proposed method.
\end{abstract}

Keywords Morphometry analysis · Basin lag time · Compound ranking method · Flood-inducing capacity index · Maximum discharge

\section{Introduction}

Flood is a geo-hydrologic process commonly observed in floodplains and deltas. On the one hand, it creates and modifies the fluvial landscape and on the other, it brings sufferings to the people [1, 2]. Frequent flooding is inherent in the Ganga-Brahmaputra Delta [3]. Every year large rivers of this delta like Ganga, Brahmaputra inundates huge area triggering the sufferings of human beings [4].
Similarly, floods of Damodar, Ajay and Mayurakshi systems are widely noted for their severity on the life and livelihood of the people. Hence, this river system is often called as the sorrow of Bengal [5]. Thus, understanding and modeling flood behaviour become vital for resource appraisal and regional planning. Though flood is primarily a hydro-meteorological hazard, basin geomorphology plays an important role in triggering floods [6]. The study of a flood using morphometric properties of drainage basin was pioneered

$\triangle$ Aznarul Islam, aznarulislam@gmail.com; Suman Deb Barman, sdbarman1993@gmail.com |'Department of Geography, Aliah University, Kolkata 700 014, India. ${ }^{2}$ The University of Burdwan, Golapbag 713104, India. 
through the works of $[7,8]$. This long-established tradition of studying flood in terms of linear, areal and relief aspects in geomorphology continues worldwide. However, recently geo-spatial techniques coupled with other field measurements are increasingly used in estimating flood hazards. Annis et al. [9] evaluated flood mapping using the digital terrain model (DTM) and stream order in Italy, Spain, and the UK. Similarly, flood mapping in the ungauged and data-sparse environment was done based on the linear binary geomorphic classifier derived from the digital elevation model $[10,11]$.

Mayurakshi River Basin (MRB) has been explored widely in terms of morphometric analysis. Pal et al. [12] found channel instability and asymmetry of the channel width of Mayurakshi, Dwaraka, and Kuye to be correlated strongly with anthropogenic activities. Besides, the flood behavior of MRB has drawn special attention for its history of colossal destruction of more than two century [13]. Flood of this basin is mainly due to the drainage congestion at the lower stretch of the river and typical basin morphometry [14]. Mukhopadhyay and Das [15] correlated occurrences of the flood with channel derangement of Mayurakshi River. Jha and Bairagya [16] depicted the spatiotemporal variation of flood and stressed the importance of paleoflood data in flood management of the data-sparse environment. Mukhopadhyay and Let [17] showed that the intensity and frequency of flood of Dwaraka River, a tributary of the Mayurakshi system were found to be increasing with time due to increasing anthropogenic activities like construction of barrages, embankment and sand mining. Kuye River, another tributary of Mayurakshi has depicted increasing flood frequency with time [18]. Similarly, flood frequency of the Mayurakshi sub-basin is increasing after the construction of Tilpara barrage [19]. The impact of this barrage is not only confined to the main channel, but the tributaries joining the master get affected by channel sedimentation and reduced cubic capacity triggering more flood in the backwaters [20]. After the construction of Massanjore dam, stretch downstream of dams portrayed significant changes in hydro-geomorphology like lowering of pre-monsoon and monsoon water level and attenuation of the duration of the peak period [20,21]. Based on a 75-year flood and rainfall data, Ghosh and Pal [22] depicted that flood of Lower Mayurakshi River has changed its character from the high magnitude low-frequency event to low magnitude high-frequency event due to controlled river regime by dams and barrages. The above literature portrays the severity of flood hazard in the MRB, especially in its lower stretch. The impact of dams and barrages on the flood is also adequately addressed. However, the role of an individual component (tributary river basins) to affect the whole system (MRB flood) is barely missing. Thus, the present research would address the following objectives:
Main objective: To assess the relative capacity of the tributary river basins in triggering a massive flood of the lower stretch of the Mayurakshi system using drainage basin morphometry.

Sub-objectives:

(i) To find out the linear, areal and relief parameters (basic and ratio) of the tributary drainage basins and identifying the main control variables,

(ii) To estimate discharge and basin lag time of the tributary basins using morphometric indices, and

(iii) To propose flood-inducing capacity index based on morphometric parameters.

\section{Study area}

Mayurakshi River has originated from Trikut Hill near Deoghar, Jharkhand and has made a confluence with the Bhagirathi River at Kalyanpur having a flow path of $250 \mathrm{~km}$. It extends from the $23^{\circ} 37^{\prime} 43^{\prime \prime} \mathrm{N}$ to $24^{\circ} 37^{\prime} 36^{\prime \prime}$ $\mathrm{N}$ latitude and $86^{\circ} 50^{\prime} 16^{\prime \prime} \mathrm{E}$ to $88^{\circ} 15^{\prime} 52^{\prime \prime} \mathrm{E}$ longitude (Fig. 1) and covers a basin area of about $9596 \mathrm{~km}^{2}$. This basin is configured by the three main rivers-Mayurakshi, Dwaraka, and Kuye. Based on the ' $V$ ' rule of Patton and Baker [23], we have demarked 13 sub-basins having a minimum order of 4 ( 8 sub-basins of Mayurakshi-M1 for Bhurbhuri River, M2 for Dhobai River, M3 for Matihara River, M4 for Tepra River, M5 for Bhamri River, M6 for Siddheswari River, M7 for Kushkarani River, M8 for Pusharo Nala; 3 sub-basins of Dwaraka- D1 for Dwaraka River, D2 for Chila-Gharmora Nala, D3 for Brahmani River and 2 sub-basins of Kuye-K1 for Kopai River and K2 for Bakreshwar River) (Fig. 1). The upper stretch of the river is a part of plateau fringe influenced by typical heavy downpour in the monsoon months especially during September and October [24]. This typical rainfall regime coupled with a low-pressure system developed over the Bay of Bengal induces floods in the basin. Apart from the classic floods at the historic time (1787 and 1806) as noted by O'Malley [25] in District Gazetteers, the study area in Mayurakhi basin is very vulnerable to flood attacks as far as previous scholarships are concerned. Moreover, the records of the District Disaster Management Plan prepared by [26] and Flood Preparedness and Management Plan by [27] coupled with the description of O'Malley [28, 25], and Walsh [29] give testimony to the severity of flood hazard in the study area and hence each flood event year and its related severity are presented in Table 1. Thus, huge monsoon discharge along with its annual sediment load of about 2.52 million tons trigger channel instability of the Mayurakshi system itself and the Lower Bhagirathi River system as well $[30,31]$. It is to note that during 


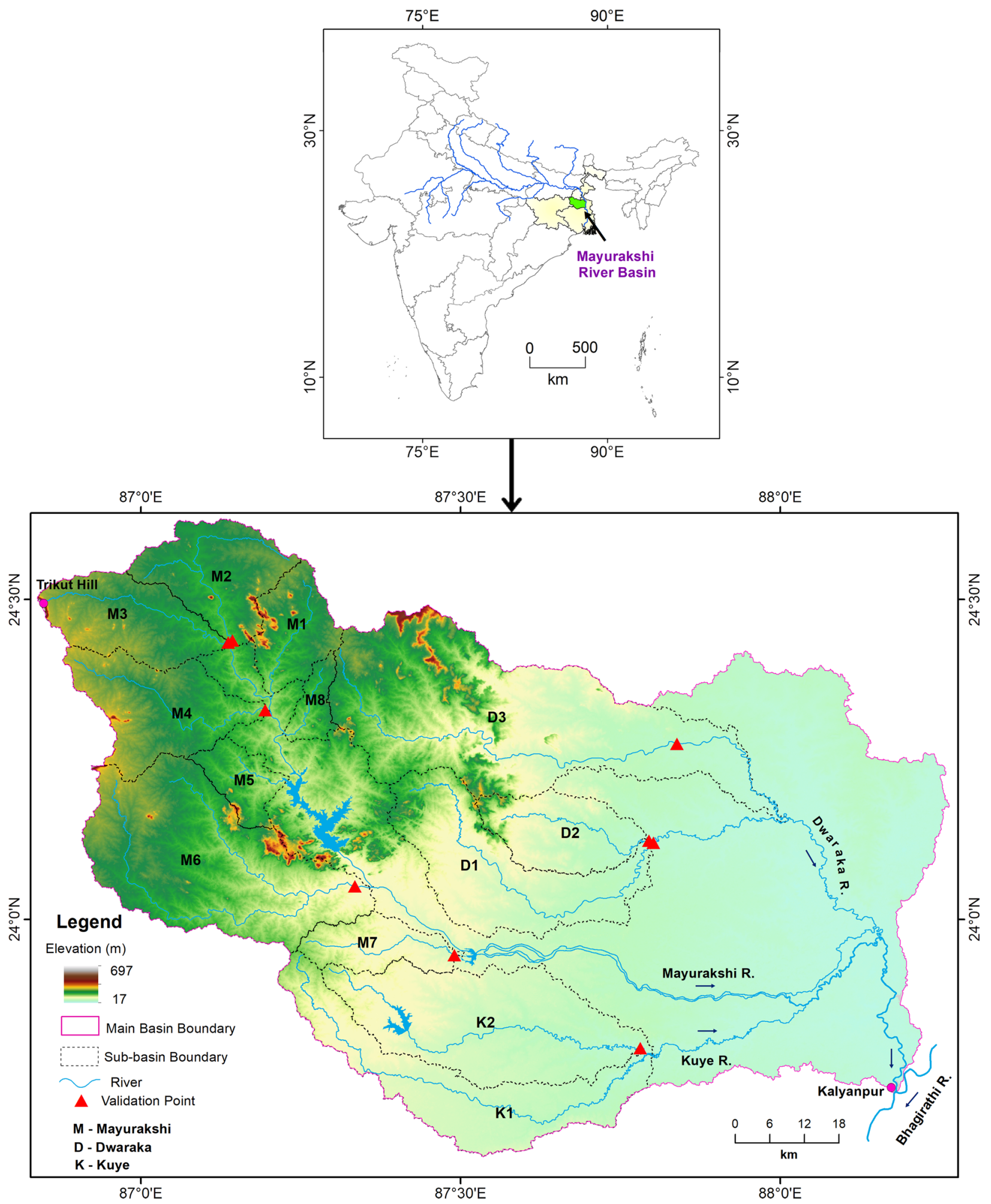

Fig. 1 Location of the tributary basins of the Mayurakshi River system and validation points

the colossal flood of 2000, the lower stretch of the basin was almost completely inundated. The total area of the basin under the flood water has been computed to be $\sim 1490 \mathrm{~km}^{2}$ during this flood (Fig. 2). Therefore, the frequent and violent floods marginalize agriculture and animal husbandry of this tropical region. 
Table 1 Historical flood events in the Mayurakshi River Basin

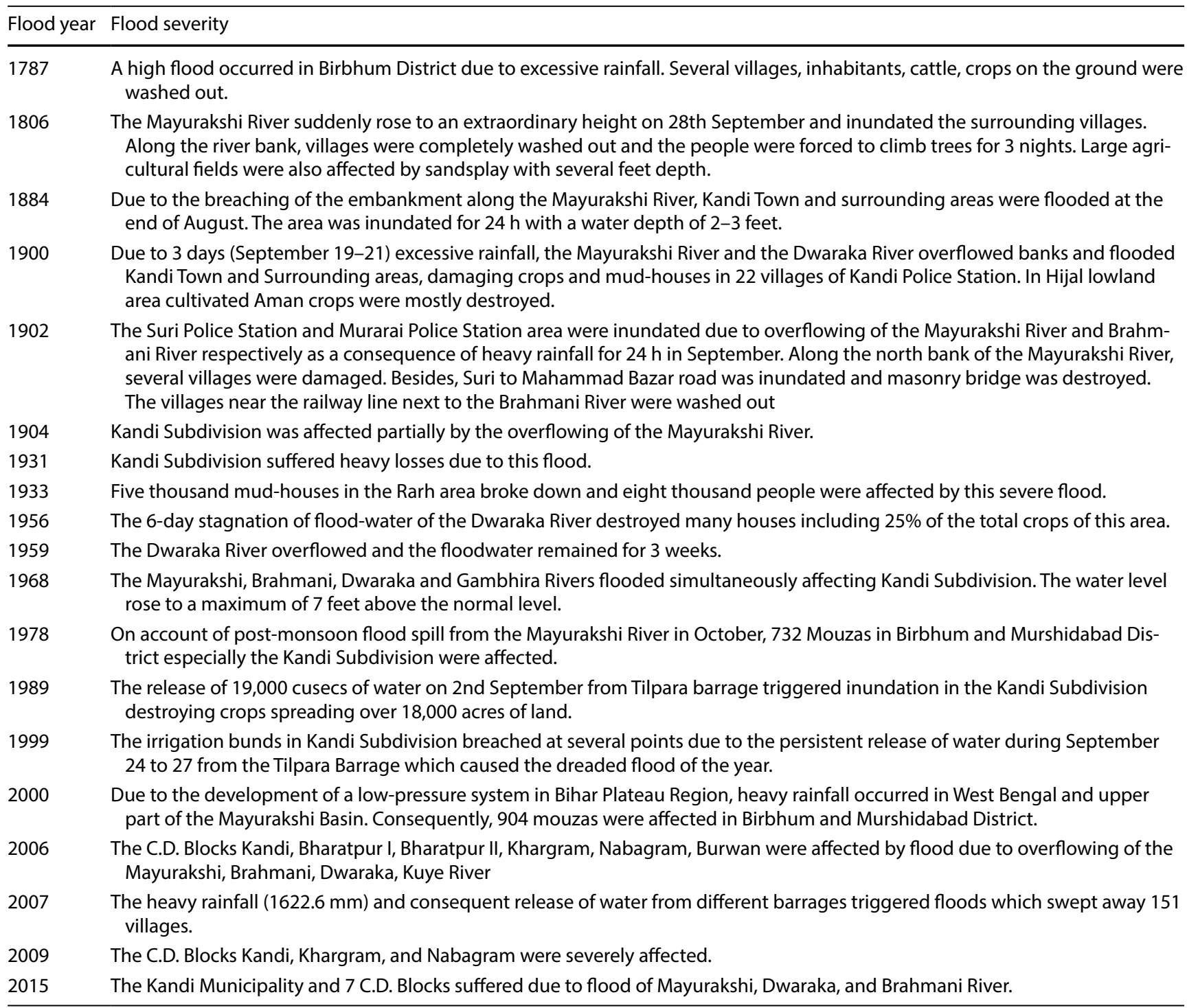

Based on the report prepared by the Office of the District Magistrate [27, 26], O'Malley [28], O'Malley [25], and Walsh [29]

\section{Database and methodology}

The present work has been carried out using a systematic methodological design that starts with the identification of the research problems and ends with the validation of the results derived through some sequential steps (Fig. 3).

\subsection{Collection of data}

The five basic morphometric parameters (basin area, perimeter, length, maximum and minimum relief, stream number and length) for the 13 tributary river basins of MRB computed from the 1:50,000 Survey of India topographical maps $(72 \mathrm{~L}-14,15,16 ; 72 \mathrm{P}-2,3,4,7,8,11$, $12,15,16 ; 73 \mathrm{M}-1,5,6,9,10,13,14 ; 78 \mathrm{D}-3,4 ; 79 \mathrm{~A}-1,2)$ and $30 \mathrm{~m}$ Shuttle Radar Topographic Mission (SRTM) Digital Elevation Model (DEM) using ArcGIS 10.4 software constitute the major source of the data for the present inquiry. Basin morphometry parameters (area, perimeter, and length) are derived through the processing of DEM using flow direction and accumulation function of the ArcGIS. Moreover, stream number and length have been measured from the topographical maps. 


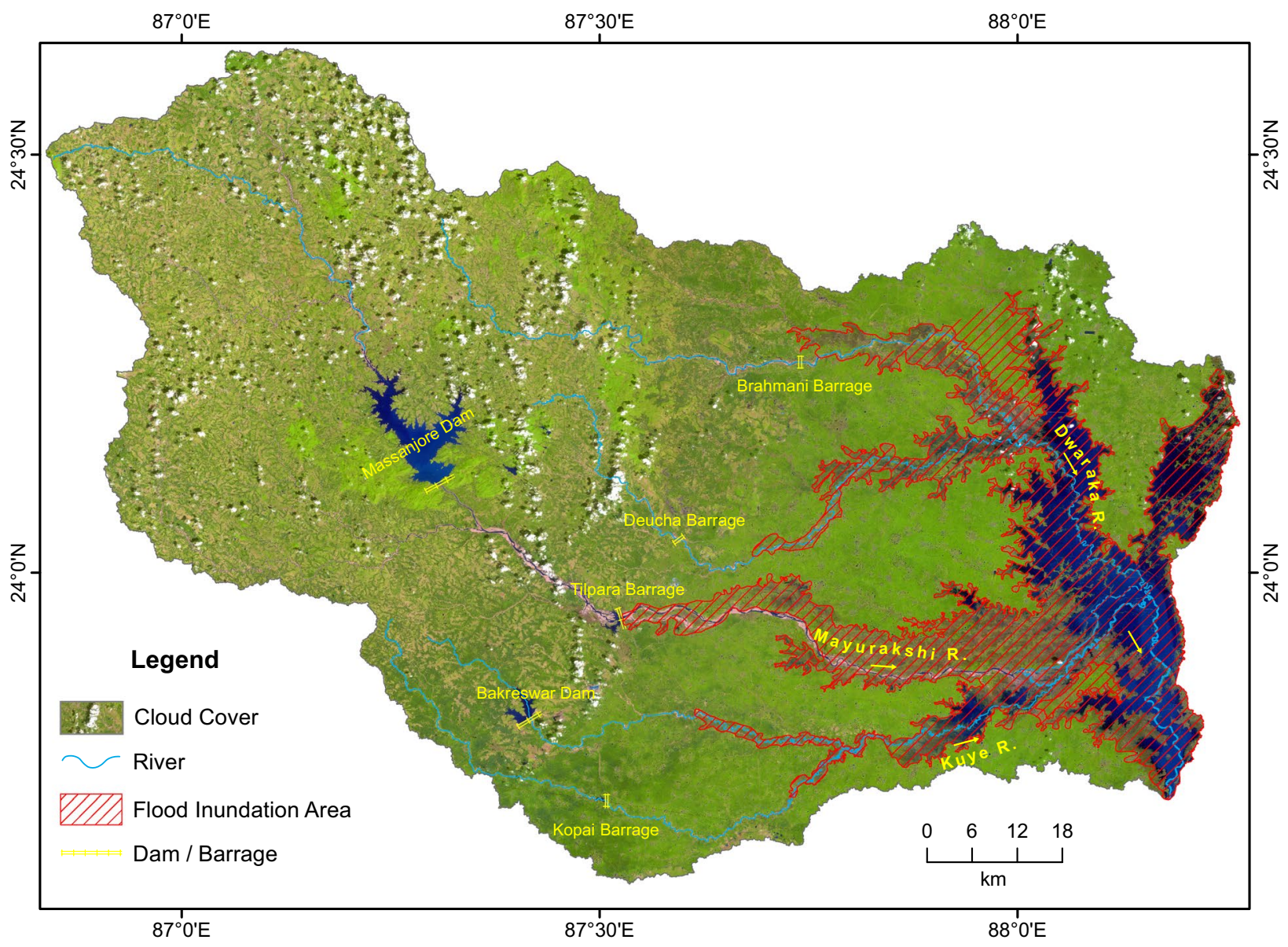

Fig. 2 Flood inundation area of the Mayurakshi River Basin in 2000 (Computed from Dartmouth Flood Observatory (DFO)-2000-061 East India and Bangladesh and Landsat 5 - path 139, row 43,44 dated 29.09.2000)

\subsection{Methods of data processing}

\subsubsection{Computation of morphometric indices}

With the help of the basic parameters, two linear, seven areal and six relief aspects/indices have been computed using the algorithms in Table 2.

\subsubsection{Estimation of discharge-related parameters}

Estimation of discharge (Q) from morphometric variables is a long-held tradition in fluvial geomorphology. Most of the previous works have estimated the discharge from the area of the drainage basin. However, depending on the climatic and hydro-geomorphic differences the coefficient and the exponent varies significantly. For example, Kirpich [43] derived $\alpha$ as 0.00032 and $\beta$ as 0.77, Chow [44] derived $\alpha$ as 0.0012 and $\beta$ as 0.64 , Kennedy and Watt [45] derived $a$ as 0.00018 and $\beta$ as 0.75 , Natural Environment Research Council [46] derived $\alpha$ as 0.0215 and $\beta$ as 0.47 . For the present case, the algorithm of Dickens as mentioned by Alexander [47] has been embraced as it was developed to compute the peak discharge $(\mathrm{Q})$ of the then Bengal province of India.

$Q=825 A 0.75$

Besides, components related to discharge is the competence of flow which can be measured in terms of computation of lag time ( $\mathrm{tL}$ ) after Watt and Chow [48] and time of concentration (tc) after National Resource Conservation Service [49] as follows:

$t L=0.000326\left(\frac{L}{\sqrt{S}}\right) 0.79$

For basins with Area (A) 0.5 ha to $5840 \mathrm{~km}^{2}$, Length (L) $100 \mathrm{~m}$ to $200 \mathrm{~km}$, and Slope (S) $0.001-0.09 \mathrm{~m} / \mathrm{m}$.

$t c=1.67 t L$ 
Fig. 3 Flowchart of the methodology

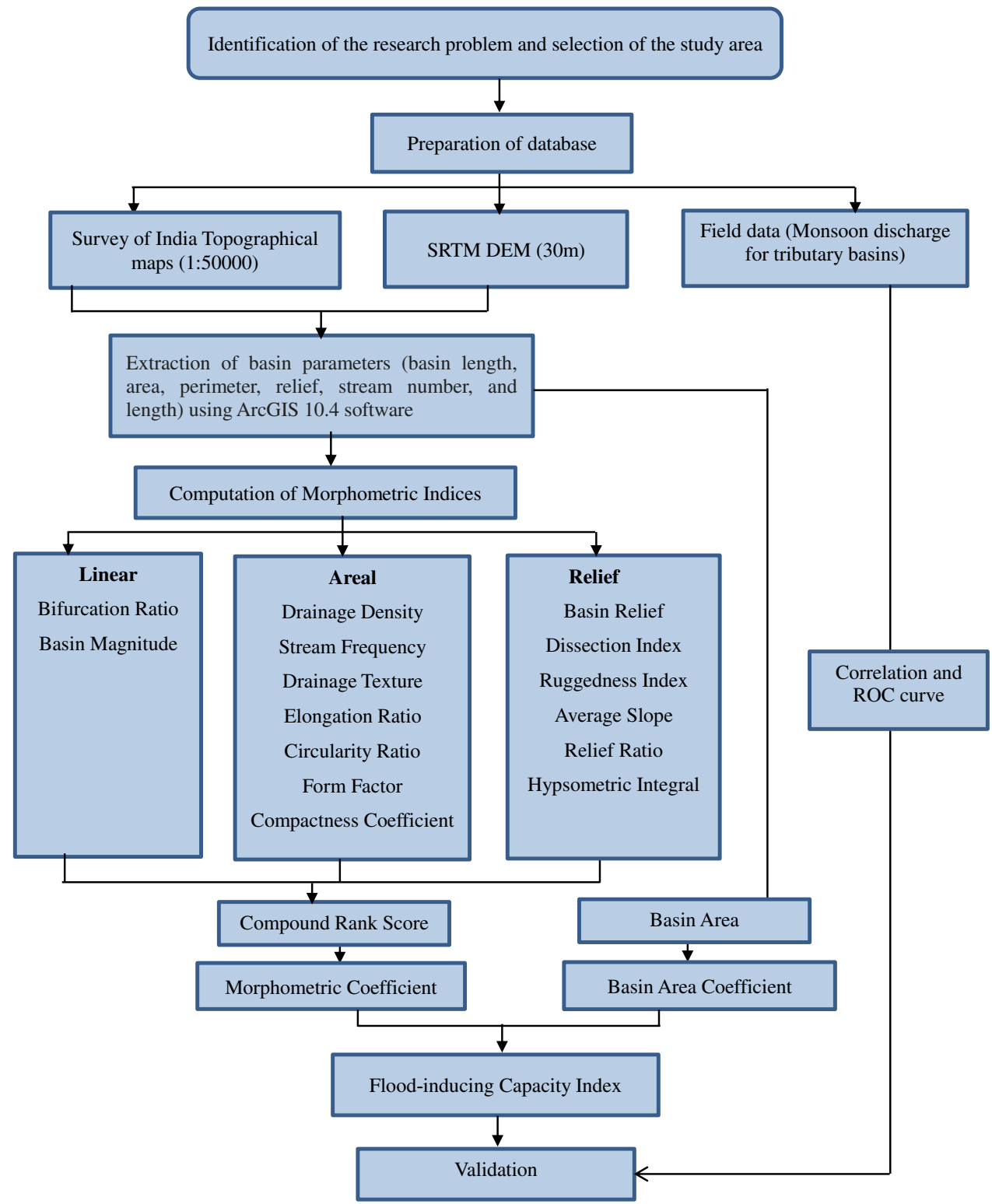

\subsubsection{Varimax rotation method}

Varimax rotation method, a popular rotation method in PCA and factor analysis, was propounded by Kaiser [50] to simplify the interpretation of variable-factor relationship. This method converts the original factor loadings into two distinct groups - a few numbers of large loading (one) and a large number of small loading (zero). Following the methodology of Kaiser [50] it has been computed as below:

$v=\sum_{a}\left\{\left[n \sum_{j}\left(a_{j s}^{2} \mid h_{j}^{2}\right) 2-\left[\sum_{j}\left(a_{j s}^{2} \mid h_{j}^{2}\right)\right] 2\right] / n^{2}\right\}$ where $j=1,2, \ldots, n$ are tests, $s=1,2, \ldots, r$ are factors, $a_{j s}$ is the factor loading of the $j$ th test on the sth factor, $h_{j}^{2}$ is the communality of the jth test

\subsubsection{Compound ranking method and flood-inducing capacity index}

To gauge the relative contribution of each tributary basin for inducing the flood of the Mayurakshi system, we have proposed an index i.e. flood-inducing capacity index $(\mathrm{FCl})$ which is computed following a few steps. First, to get the compound rank $(\mathrm{Cr})$ of each river basin, the compound ranking method, a popular technique to portray the ordering of the data [51], has been embraced for the present case. Thus, the compound rank of each 
Table 2 Methods for computing morphometric indices

\begin{tabular}{|c|c|c|c|c|}
\hline SI. No. & Dimensions & Parameters & Algorithms & References \\
\hline 1 & \multirow[t]{2}{*}{ Linear } & Basin magnitude (BM) & $\begin{array}{l}B M=\Sigma N \mu i \\
N \mu=\text { Number of stream; i for First order }\end{array}$ & {$[32]$} \\
\hline 2 & & Bifurcation ratio (BR) & $\begin{array}{l}B R=\frac{N_{\mu}}{N_{\mu+1}} \\
N_{\mu}=\text { Number of stream of a certain order; } N_{\mu+1}=\text { Number of stream in } \\
\text { next higher order }\end{array}$ & [33] \\
\hline 3 & \multirow[t]{8}{*}{ Areal } & Drainage density (DD) & $\begin{array}{l}D D=\frac{\Sigma L}{A} \\
L=\text { Length of the rivers; } A=\text { Basin area }\end{array}$ & {$[34]$} \\
\hline 4 & & Stream frequency (SF) & $\begin{array}{l}S F=\frac{\Sigma N}{A} \\
N=\text { Number of stream segments; } A=\text { Basin area }\end{array}$ & [34] \\
\hline 5 & & Drainage texture (DT) & $\begin{array}{l}D T=\frac{N \mu}{P} \\
N \mu=\text { Total number of stream segments; } \mathrm{P}=\text { Basin perimeter }\end{array}$ & {$[35]$} \\
\hline 6 & & Elongation ratio (ER) & $\begin{array}{l}E R=\frac{\Pi R 2}{4} \\
\mathrm{R}=\text { Diameter of an equivalent circular area }\end{array}$ & [33] \\
\hline 7 & & Circularity ratio (CR) & $\begin{array}{l}C R=\frac{4 \Pi A}{P 2} \\
P=\text { Basin perimeter, } A=\text { Basin area }\end{array}$ & [36] \\
\hline 8 & & Form factor (FF) & $\begin{array}{l}F F=\frac{A}{L 2} \\
A=\text { Basin area; } L=\text { Basin length }\end{array}$ & [34] \\
\hline \multirow[t]{2}{*}{9} & & Compactness coefficient (CC) & $C C=0.2821\left(\frac{P}{A}\right) 0.5$ & [37] \\
\hline & & & P Perimeter of the basin $A=$ Basin area; & \\
\hline 10 & \multirow[t]{6}{*}{ Relief } & Relative relief (RR) & $\begin{array}{l}R R=H x-L x \\
H x=\text { Maximum relief; } L x=\text { Minimum relief }\end{array}$ & [38] \\
\hline 11 & & Dissection index (DI) & $\begin{array}{l}D I=\frac{R R}{H x} \times 100 \\
\mathrm{Hx}=\text { Maximum relief; } \mathrm{RR}=\text { Relative relief }\end{array}$ & [39] \\
\hline 12 & & Ruggedness number (RN) & $\begin{array}{l}R N=\frac{R R \times D D}{K} \\
\mathrm{~K}=\text { a conversion constant }(1000) ; \mathrm{RR}=\text { Relative relief; } \mathrm{DD}=\text { Drainage } \\
\text { density }\end{array}$ & {$[40]$} \\
\hline 13 & & Average slope (AS) & $\begin{array}{l}A S=\tan ^{-1} \frac{N x i}{K} \\
N \text { for Number of contour crossing per km; i for contour interval; } K \text { for } \\
\text { constant (636.6) }\end{array}$ & [41] \\
\hline 14 & & Relief ratio (RT) & $\begin{array}{l}R T=\frac{R R}{L} \\
\text { RR Relative relief of a basin; } L \text { Basin length. }\end{array}$ & {$[33]$} \\
\hline 15 & & Hypsometric integral (HI) & $\begin{array}{l}H I=\frac{L S}{L u s} \\
L S=\text { Percentage of area uneroded } ; \text { Lus = Percentage of area eroded }\end{array}$ & [42] \\
\hline
\end{tabular}

sub-basin is derived through the summation of the rank score (assigned according to flood-inducing capacity) of each morphometric variable following a ranking principle (Table 8). Second, the basin area coefficient has been computed as a ratio of the individual basin area to the total basin area. Third, the morphometric coefficient has been computed as a ratio of the compound rank of an individual basin to the compound rank of the total basin. Finally, the computation of $\mathrm{FCl}$ takes the consideration of basin area coefficient and basin morphometry coefficient. Theoretically, the higher the basin area coefficient the higher the potential discharge. However, the nature of flow (sustained or peak) depends on the morphometry coefficient which also directly controls the pace of flow. Therefore $\mathrm{FCl}$ is conceived as a multiplied form of the coefficients and may be equated as follows. $c r j=\sum_{i=1}^{n} r i$

$F C l j=\left(\frac{a j}{A}\right) \times\left(\frac{c r j}{C R}\right)$

where $c r j$ stands for the compound rank score for $j$ subbasin; i for morphometric parameters, and $r$ for the rank of the ith parameters; FClj for the flood-inducing capacity of the $j$ th basin, aj area of the $j$ th sub-basin, A for total basin area accounted for by all tributary basins, CR for total compound rank score accounted for by the all tributary basins.

Theoretically, the index value will range from ' 0 ' to ' 1 ', but these extreme values are never reached in the real situation. Regarding basin area coefficient $\left(\frac{a j}{A}\right),{ }^{\prime} 0$ ' signi- 
fies no basin area for the sub-basin $\mathrm{j}$ and therefore no potential discharge and ' 1 ' signifies $a j=A$ and total potential discharge through the sub-basin $j$. Concerning the morphometry coefficient $\left(\frac{c r j}{C R}\right)$, ' 0 ' indicates no flow and ' 1 ' extremely peaked flow. And regarding $\mathrm{FCl}$, ' 0 ' implies no flood-inducing capacity while ' 1 ' for maximum flood-inducing capacity.

\subsubsection{Validation techniques}

For validating the results of the $\mathrm{FCl}$, maximum discharge $\left(Q_{M}\right)$ following a rainstorm was measured as an indicator of flood-inducing capacity at the outlet of the selected 9 drainage basins (Fig. 1) during the monsoon period (September 2019). To gauge maximum flow, the discharge was measured a day after the rain started taking the consideration of flow concentration. Doing with that, first, the cross-sections were undertaken using an Auto level and surface velocity was taken by float method. Then, the cross-sectional area (A) concerning wetted perimeter was computed using trapezoid method while the mean velocity $(\mathrm{V})$ was obtained through the multiplication of the surface velocity with a commonly used constant 0.85 [52]. Thus, the maximum discharge $\left(Q_{M}\right)$ is calculated as follows.

$Q_{M}=A \times V$

Finally, the observed discharge was compared with the computed $\mathrm{FCl}$ using a bivariate correlation. And the validity of ' $r$ ' was tested using Student's $t$ test as follows.

$t=\sqrt{\frac{r^{2}(N-2)}{1-r^{2}}}$

where $r=$ correlation of coefficient, $N=$ number of observations.

Besides, the validation check is necessary to estimate the level of accuracy of the proposed FCl method. Thus, we have applied the receiver operating characteristics (ROC) curve which plots true positive rates (TPR) against the false positive rate (FPR) against different threshold points. The area under the curve is categorized as-excellent (0.90-1.00), good (0.80-0.90), fair (0.70-0.80), poor $(0.60-0.70)$ and fail $(0.50-0.60)$ for showing the level of accuracy [53]. For this present work, ROC has been prepared using IBM SPSS Statistics 20 software.

\section{Results and discussion}

\subsection{Basin morphometry}

The study of basin morphometry has a legacy in quantitative geomorphology for understanding the hydro-dynamics of a drainage basin. The classical approach to comprehend the fluvial response within a basin involves the careful consideration of the linear, areal and relief aspects. In the present context, we have attempted to study two linear, seven areal and six relief parameters/indices to trace out their role on flood-inducing capacity of the tributary basins. The 15 morphometric variables are presented uniformly concerning their spatial variation and descriptive statistics. The first parameter involves stream order, number, and length. Strahler basin order (highest stream order of a basin after Strahler) is positively correlated with peak discharge $[54,55]$. In the MRB, D3, M2, M3, M5, and M6 have basin order above 6. However, Baker and Patton [23] found that Strahler order is not a good measure of flood peak because it does not have any control over basin topology. Thus, Shreve magnitude (number of the firstorder streams of a basin after Shreve) was found to be strongly correlated with the flood discharge. In the MRB, D1, M3, M4, and M7 basins have higher Shreve magnitude per unit basin area with their correspondingly effect on the flood. Furthermore, the stream order is indirectly correlated with the stream number and length (Fig. 4a, b). The order-number relationship is strongly negative $\left(r^{2}>0.95\right)$ while the order-length relationship is also negative with a variable degree of correlation (Table 3 ). For example, the basin $\mathrm{K} 1$ portrays a poor relation $\left(r^{2}=0.16\right)$ while basin $\mathrm{K} 2$, $\mathrm{D} 1$ and $\mathrm{M} 3$ also have a moderate degree of relation $\left(0.5<r^{2}<0.80\right)$. However, the rest of the sub-basins portray $r^{2}>0.90$. Moreover, if we look into the ratio of first-order stream number and length to that of the total, it appears that more than $70 \%$ streams are first order having the highest for M6 $(n=1506)$ river and lowest for M8 $(n=106)$. However, the ratio regarding length portrayed that about $50 \%$ of the total is the first-order length having the highest for M6 $(969.13 \mathrm{~km})$ and lowest for M8 $(65.50 \mathrm{~km})$. Regarding length ratio, the Dwaraka and Kuye are located well below $50 \%$ (Fig. 4c). Similarly, concerning the average bifurcation ratio a moderate degree of the range and standard deviation (SD) is observed (Table 4) and is spatially segregated into low (2.5-3.99), medium (4-5.49) and high (5.5-6.99) classes (Fig. 5a). The higher the bifurcation ratio, the lesser the flood magnitude in the lower reaches of the river. We have also computed order wise bifurcation ratio which shows that the median bifurcation ratio is decreasing with higher order. The range, quartile 1 and quartile 3 and median have been plotted on boxplot 
Fig. 4 Spatial dynamics in stream order. a Stream order in relation to stream number, b Stream order in relation to steam length, c Basin-wise first order stream number and stream length to total

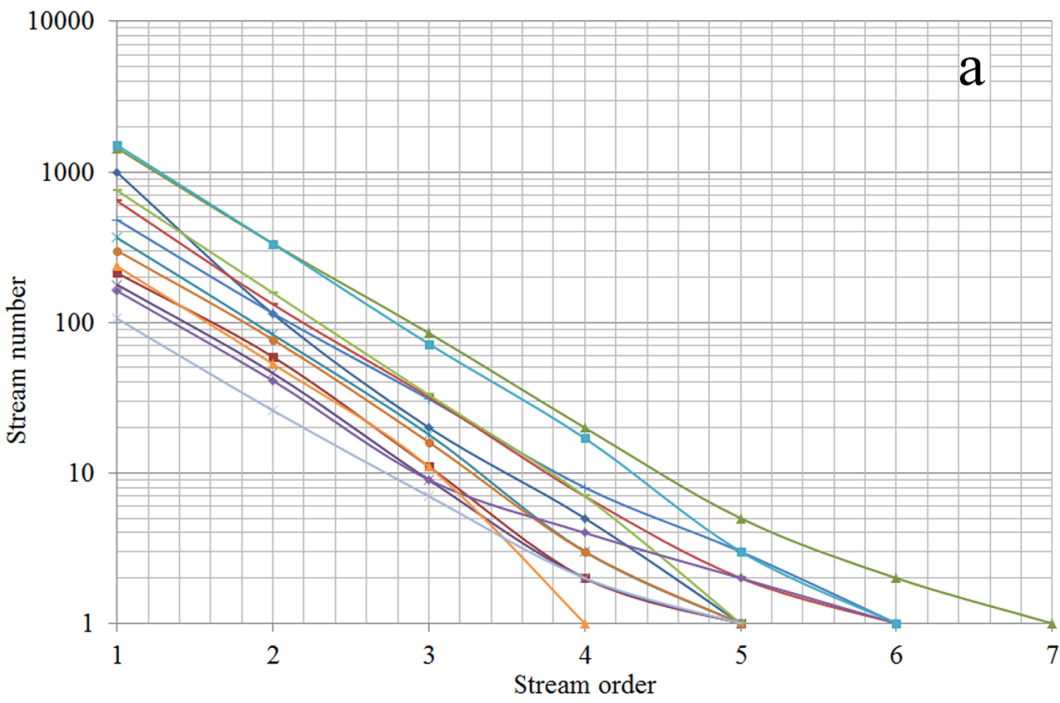

$\rightarrow$ D1

$-\mathrm{D} 2$

$-\mathrm{D} 3$

$* \mathrm{~K} 1$

$-\mathrm{K} 2$

$\rightarrow \mathrm{M} 1$

$+\mathrm{M} 2$

- M3

$-\mathrm{M} 4$

$\rightarrow \mathrm{M} 5$

$\rightarrow-\mathrm{M} 6$

$-\mathrm{M} 7$

$* \mathrm{M} 8$

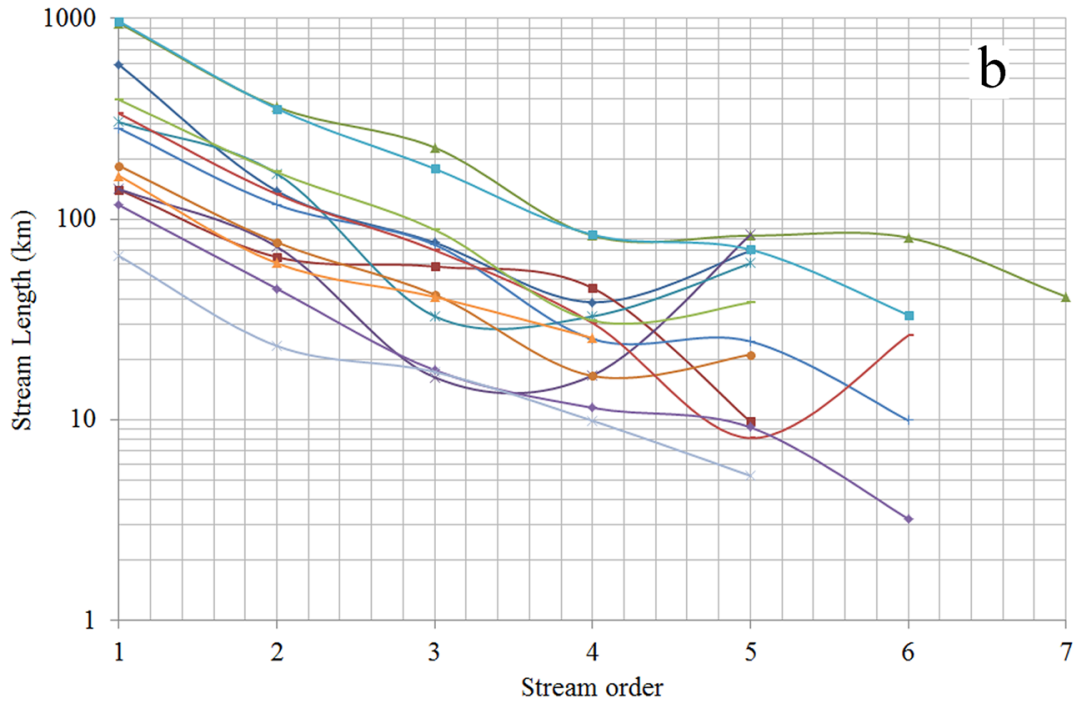

$\rightarrow-\mathrm{D} 1$

$\rightarrow-\mathrm{D} 2$

$-\mathrm{D} 3$

-K1

$* \mathrm{~K} 2$

$\rightarrow-\mathrm{M} 1$

$+\mathrm{M} 2$

$-\mathrm{M} 3$

- M4

$\rightarrow$ M5

$-\mathrm{M} 6$

$-\mathrm{M} 7$

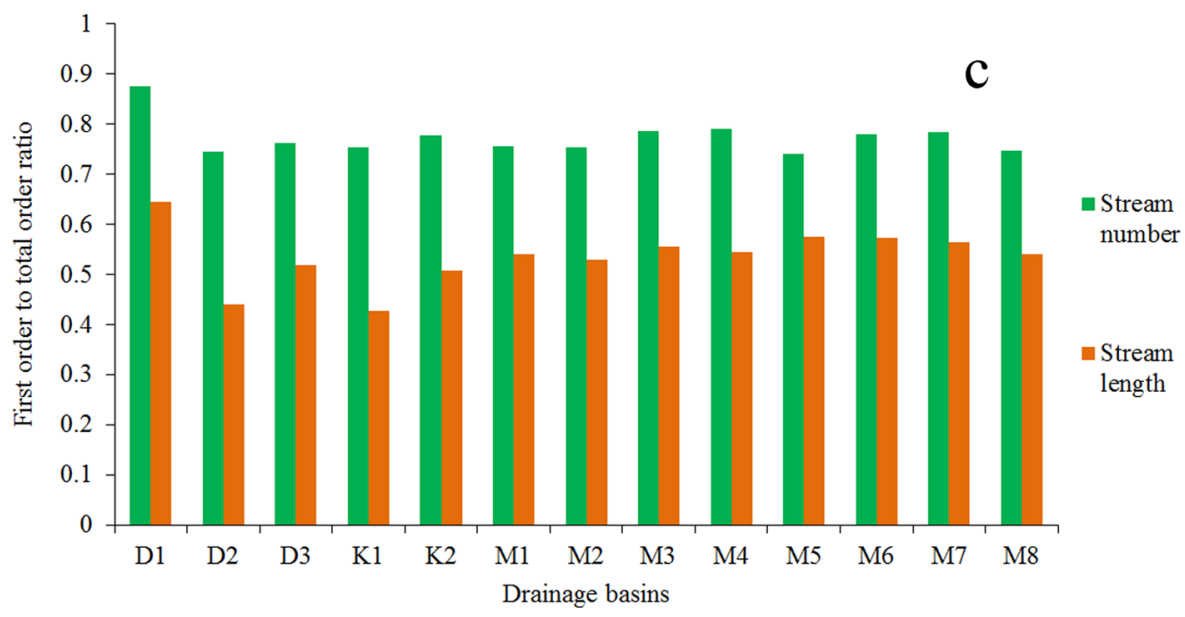

(Fig. 5b) which portrays that the range of the data is high for the $4 / 5^{\text {th }}$ order ratio. The drainage density strongly controls flood magnitude in two opposite ways. On the one hand, higher density coupled with high slope transfers water quickly towards downstream thereby inducing peak discharge in the lower stretch. On the other, higher density with minimum slope retains water in the concerned basin itself. However, theoretical debates indicate that the higher density increases drainage response thereby producing flood peaks. In the Mayurakshi Basin, the spatiality 
Table 3 Relationship between stream order, stream number, and stream length

\begin{tabular}{|c|c|c|c|c|}
\hline \multirow[t]{2}{*}{ Sub-basin } & \multicolumn{2}{|c|}{$\begin{array}{l}\text { The relation between } \\
\text { stream order and stream } \\
\text { number }\end{array}$} & \multicolumn{2}{|c|}{$\begin{array}{l}\text { The relation between } \\
\text { stream order and stream } \\
\text { length }\end{array}$} \\
\hline & Equation & $\mathrm{R}^{2}$ & Equation & $\mathrm{R}^{2}$ \\
\hline D1 & $4133.5 e^{-1.693 x}$ & 0.9931 & $584.99 e^{-0.555 x}$ & 0.7147 \\
\hline $\mathrm{D} 2$ & $843.93 e^{-1.411 x}$ & 0.9852 & $259.3 e^{-0.568 x}$ & 0.8478 \\
\hline D3 & $3803.3 e^{-1.246 x}$ & 0.9875 & $1027.6 e^{-0.48 x}$ & 0.9047 \\
\hline K1 & $620.1 e^{-1.35 x}$ & 0.9854 & $100.51 e^{-0.252 x}$ & 0.1618 \\
\hline $\mathrm{K} 2$ & $1632 e^{-1.512 x}$ & 0.996 & $346.29 e^{-0.487 x}$ & 0.5925 \\
\hline M1 & $1312.4 e^{-1.465 x}$ & 0.9963 & $268.25 e^{-0.587 x}$ & 0.8944 \\
\hline M2 & $1393.3 e^{-1.234 x}$ & 0.9956 & $475.46 e^{-0.644 x}$ & 0.9695 \\
\hline M3 & $1898.5 \mathrm{e}^{-1.326 \mathrm{x}}$ & 0.988 & $470.08 e^{-0.628 x}$ & 0.7959 \\
\hline M4 & $4150.7 e^{-1.636 x}$ & 0.9978 & $629.53 e^{-0.636 x}$ & 0.912 \\
\hline M5 & $302.07 e^{-1.009 x}$ & 0.9681 & $180.99 e^{-0.663 x}$ & 0.9628 \\
\hline M6 & $6447.5 e^{-1.49 x}$ & 0.9979 & $1432.5 e^{-0.642 x}$ & 0.9702 \\
\hline M7 & $1718.1 \mathrm{e}^{-1.796 x}$ & 0.9858 & $252.64 e^{-0.597 x}$ & 0.9496 \\
\hline M8 & $292.85 \mathrm{e}^{-1.189 \mathrm{x}}$ & 0.9872 & $99.261 e^{-0.59 x}$ & 0.9706 \\
\hline
\end{tabular}

Computed by the authors, 2018

of the drainage density is recorded through low (0.5-0.99), medium (1-1.49) and high (1.5-1.99) classes (Fig. 6a) and thus portraying their corresponding roles on the flood. The fourth is the stream frequency indicating a relative presence of stream segments in a particular basin and has similar control over flood frequency and magnitude like drainage density. In the MRB, the spatial heterogeneity is measured through low (0-0.99), medium (1-1.99) and high
(2-2.99) classes (Fig. 6b) to relate it with the flood. Similarly, the drainage texture denotes the relative spacing of the drainage lines in an area. It may be fine or coarse depending on the evolutionary history of the basin, climate and rock type [56]. The wide range and the SD are notable (Table 4) and its spatial segregation into low (0-1.99), medium (2-3.99), and high (4-5.99) is also remarkable (Fig. $6 \mathrm{c}$ ). The elongation ratio (ER) signals about the basin shape. Schumm [33] indicated that the higher the value of ER the higher the circularity of the basins. The MRB is constituted by diversified tributary basin shape and hence ER ranges from 0.44 (K1) to 0.93 (M2) (Table 4). The spatiality of the ER is noted through low (0.4-0.59), medium (0.6-0.79), and high (0.8-0.99) categories (Fig. $6 \mathrm{~d}$ ). The previous scholastic works are in wide agreement that the higher the circularity, the higher is the flood peak and vice versa. The circularity ratio (CR) signifies structural control and stages of basin evolution. The higher the $C R$, the higher is the structurally controlled drainage system besides its advanced stage of evolution. It also greatly determines the flood potency in a way similar to the elongation ratio. For example, the higher $C R$ is often marked as inducing peakedness in the discharge. In the MRB, the circularity ratio ranges from 0.42 (M1) to 0.14 (K1) and segregated into three categories-low (0.1-0.24), medium (0.25-0.39), and high (0.4-0.54) with their corresponding effects on flood (Fig. 6e). The form factor is another dimensionless ratio indicative of basin shape. For the Mayurakshi Basin, the form factor ranges from 0.68 (M2) to 0.15 (K1) basin. The sub-basins are clubbed into low (0.1-0.29), medium (0.3-0.49), and high (0.5-0.69)
Table 4 Descriptive statistics of the morphometric variables

\begin{tabular}{lrrrrrr}
\hline Morphometric variables & Average & SD & Minimum & Maximum & Kurtosis & Skewness \\
\hline Basin magnitude/basin area (BM) & 1.33 & 0.53 & 0.32 & 2.03 & -0.27 & \multicolumn{1}{c}{0.69} \\
Average bifurcation ratio (BR) & 4.32 & 1.08 & 2.95 & 6.76 & 0.82 & 1.10 \\
Drainage density (DD) & 1.52 & 0.41 & 0.60 & 1.93 & 1.00 & -1.34 \\
Stream frequency (SF) & 1.72 & 0.66 & 0.43 & 2.58 & -0.03 & -0.83 \\
Drainage texture (DT) & 2.85 & 1.47 & 0.25 & 4.92 & -0.48 & -0.50 \\
Elongation ratio (ER) & 0.64 & 0.12 & 0.44 & 0.93 & 2.67 & 1.05 \\
Circularity ratio (CR) & 0.31 & 0.08 & 0.14 & 0.42 & -0.17 & -0.69 \\
Form factor (FF) & 0.33 & 0.13 & 0.15 & 0.68 & 4.28 & 1.71 \\
Compactness coefficient (CC) & 1.86 & 0.33 & 1.56 & 2.73 & 3.25 & 1.71 \\
Relative relief (RR) & 322.77 & 158.30 & 98.00 & 604.00 & -0.47 & 0.34 \\
Dissection index (DI) & 0.80 & 0.11 & 0.62 & 0.97 & -1.33 & 0.05 \\
Ruggedness number (RN) & 0.26 & 0.15 & 0.06 & 0.54 & -0.50 & 0.57 \\
Average slope (AS) & 1.85 & 0.68 & 0.75 & 3.13 & -0.18 & 0.02 \\
Relief ratio (RT) & 10.39 & 5.54 & 2.24 & 18.19 & -1.22 & -0.21 \\
Hypsometric integral (HI) & 0.23 & 0.09 & 0.13 & 0.42 & 0.14 & 0.94 \\
\hline
\end{tabular}




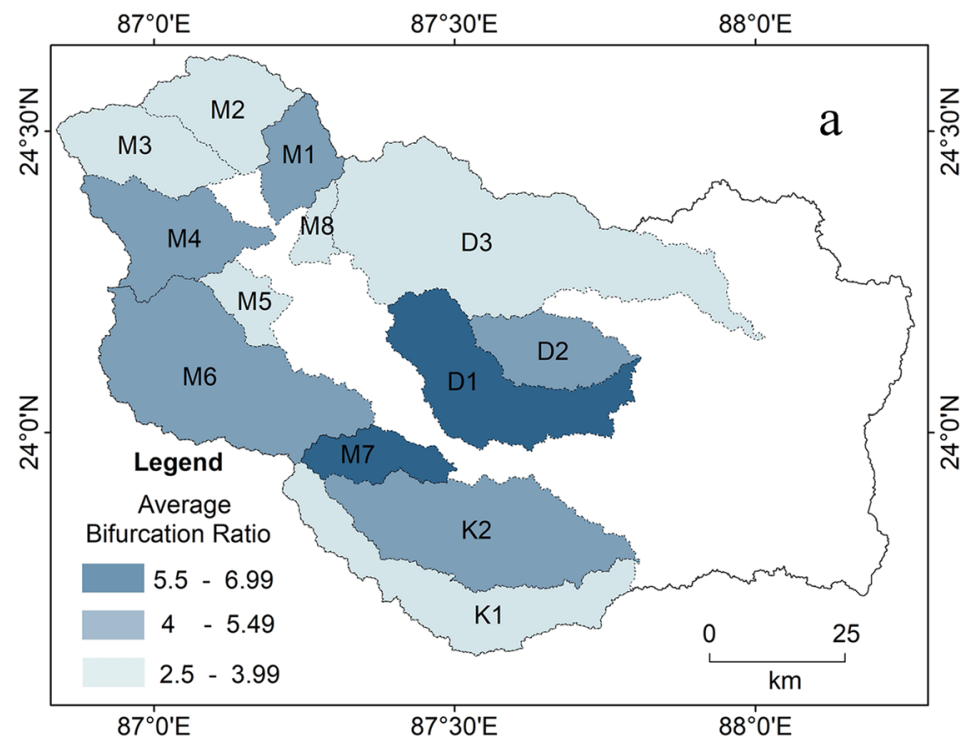

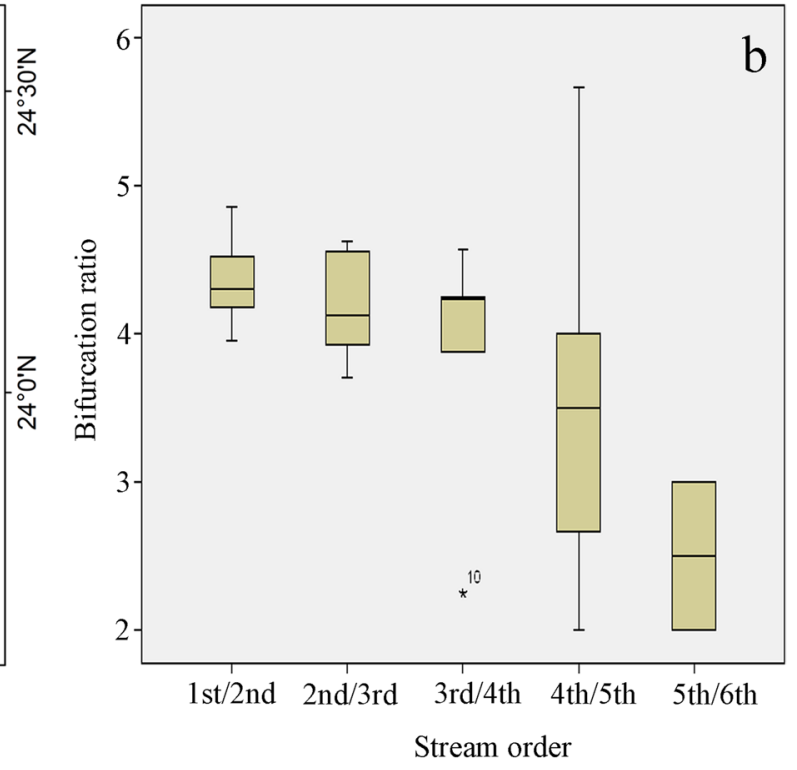

Fig. 5 Bifurcation ratio. a Basin-wise average, b Order-wise distribution

categories (Fig. 6f). The higher the value the greater the circularity and hence higher flood potency. Moreover, the compactness coefficient (CC) is a good measure of basin efficacy to the hydrologic response. If the value of this measure becomes 1 the basin would be perfectly circular and the basins having a value greater than this limit tend to be elongated [37]. In the MRB, the compactness coefficient ranges from 2.7 (K1) to 1.6 (M1) basin implying none of the sub-basins having circular shape. The wide variation is segregated into low (1.5-1.99), medium (2-2.49), and high (2.5-2.99) categories (Fig. 7a) with an implication that the lower the value the greater the flood potency. Furthermore, basin relief and slope have long been recognized as important hydrologic parameters. The previous works of Sherman [57], Horton [56] and Strahler [58] indicate that higher basin relief leads to lower time of concentrations of surface run-off and thus producing higher flood peaks. In the MRB, the relative relief ranges from $604 \mathrm{~m}$ (M6) to $98 \mathrm{~m}$ (M7) basin. Due to the wide variations in the relief we have segregated the sub-basins into three classes-low (50-249), medium (250-449), and high (450-649) (Fig. 7b). Similarly, the dissection index ranges from 0.97 (D3) to 0.62 (M7) basin (Table 4). For the present study, there are three graduated classes of dissection index-low (0.55-0.69), medium (0.7-0.84), and high (0.85-0.99) (Fig. 7c). The higher DI induces more flood potency. Ruggedness number is the product of basin relief and drainage density [59]. It is one of the important relief parameters controlling the floods of record. In general, the higher value of this ratio induces flood peak. Patton [60] stated that a highly dissected basin of low relief is as rugged as that of a basin with a moderately dissected area of high basin relief. In the MRB the ruggedness number ranges from 0.54 (M6) to 0.06 (M7) with a high SD (Table 4). Based on the observation of the ruggedness number of the individual drainage basin, they have been segregated into three classes- low $(0-0.24)$, medium (0.25-0.49), and high (0.5-0.74) (Fig. 7d). The basins having higher ruggedness number produce more flood peak. The average slope is an important determinant of flood magnitude as it increases the flow competence of the river by decreasing the time of concentration of surface run-off [57]. For the present basin, the average slope ranges from $\sim 3^{\circ}(\mathrm{M} 1)$ to $\sim 1^{\circ}(\mathrm{K} 1)$. The division of sub-basins into low $\left(0.5^{\circ}-1.49^{\circ}\right)$, medium $\left(1.5^{\circ}-2.49^{\circ}\right)$, and high $\left(2.5^{\circ}-3.49^{\circ}\right)$ categories portrays the spatiality of the average slope (Fig. 7e). The higher the basin slope the higher the flood peak. Reliefratio is another important tool in assessing the floods especially in the diverse hydrologic and physiographic control [23] in the way similar to the average slope. In the MRB, relief ratio ranges from 18.19 (M5) to 2.24 (K2) with a high SD (Table 4) and segregated into three classes-low (0-7.49), medium (7.5-14.99), and high (15-22.49) (Fig. 7f). The last parameter is hypsometric integral (HI) which defines the stages of geomorphic evolution of the landscape. After [42], the value of HI less than 0.35 denotes old, $0.35-0.60$ indicates mature and greater than 0.60 implies youth. In the MRB, the hypsometric integral ranges from 0.42 (M7) to 0.13 (M3). The spatiality 

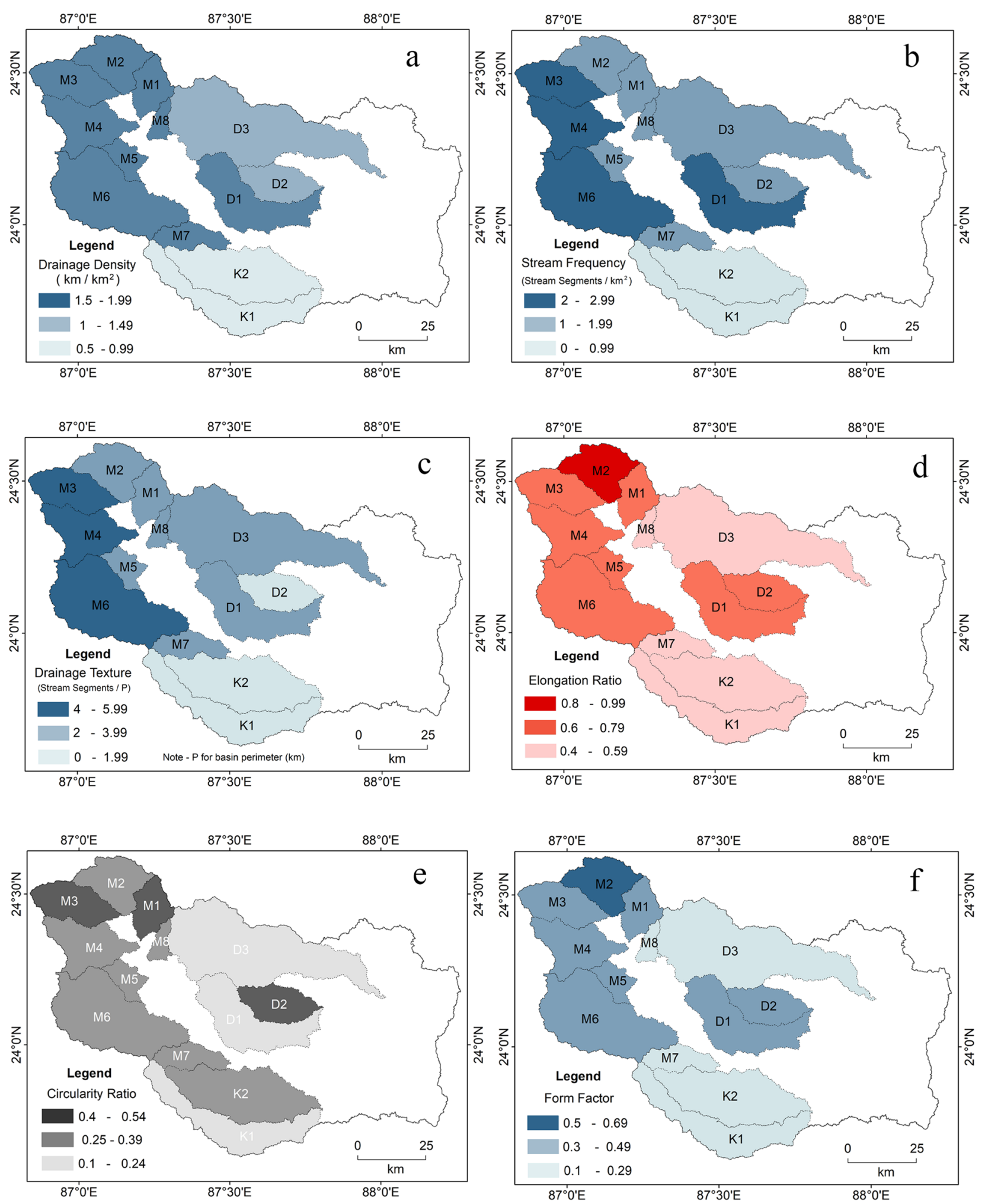

Fig. 6 Drainage characteristics and basin shape. a Drainage density, b Stream frequency, c Drainage texture, $\mathbf{d}$ Elongation ratio, e Circularity ratio, $\mathbf{f}$ Form factor 

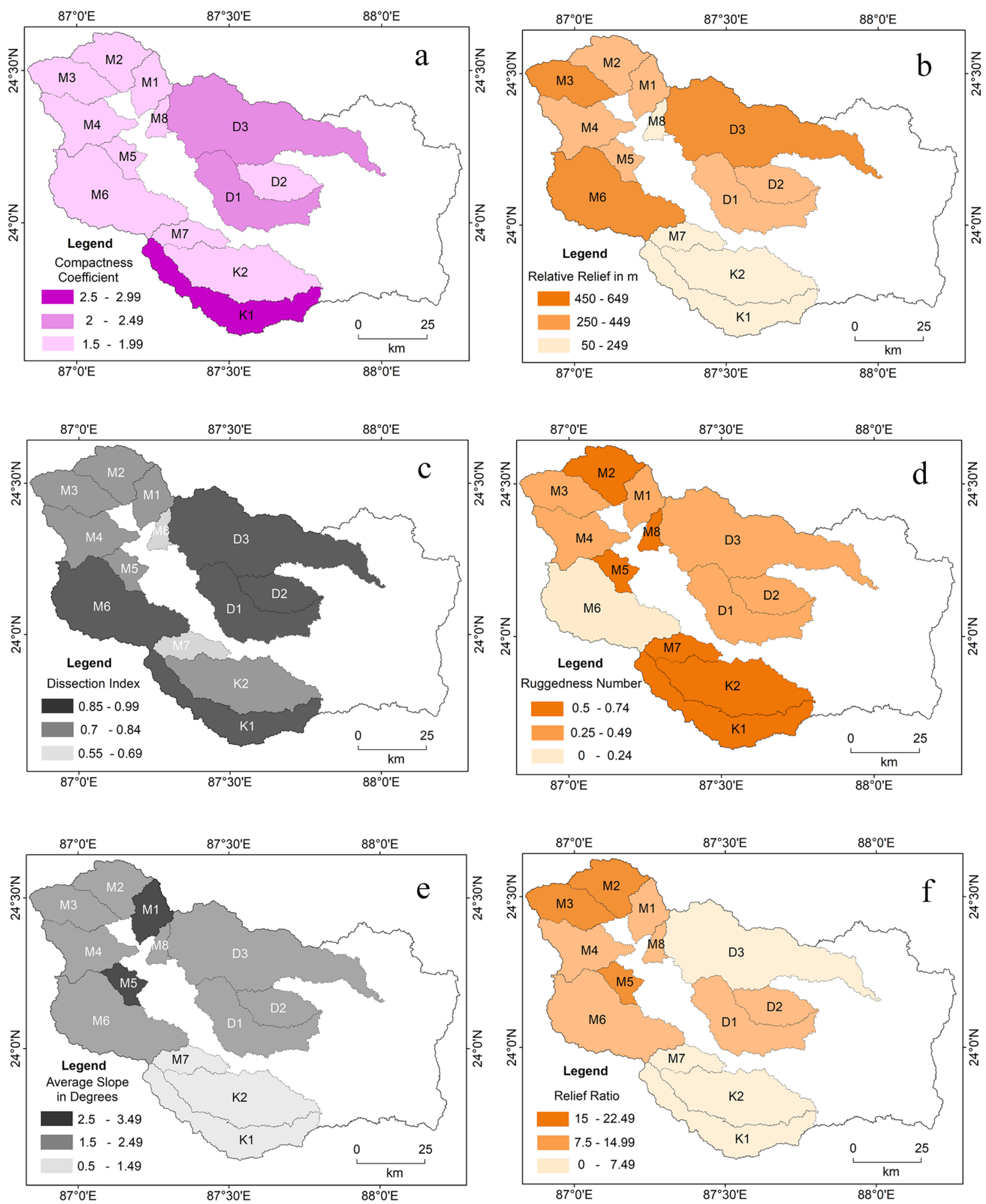

Fig. 7 Basin relief. a Compactness coefficient, b Relative relief, c Dissection index, $\mathbf{d}$ Ruggedness number, e Average slope, $\mathbf{f}$ Relief ratio 

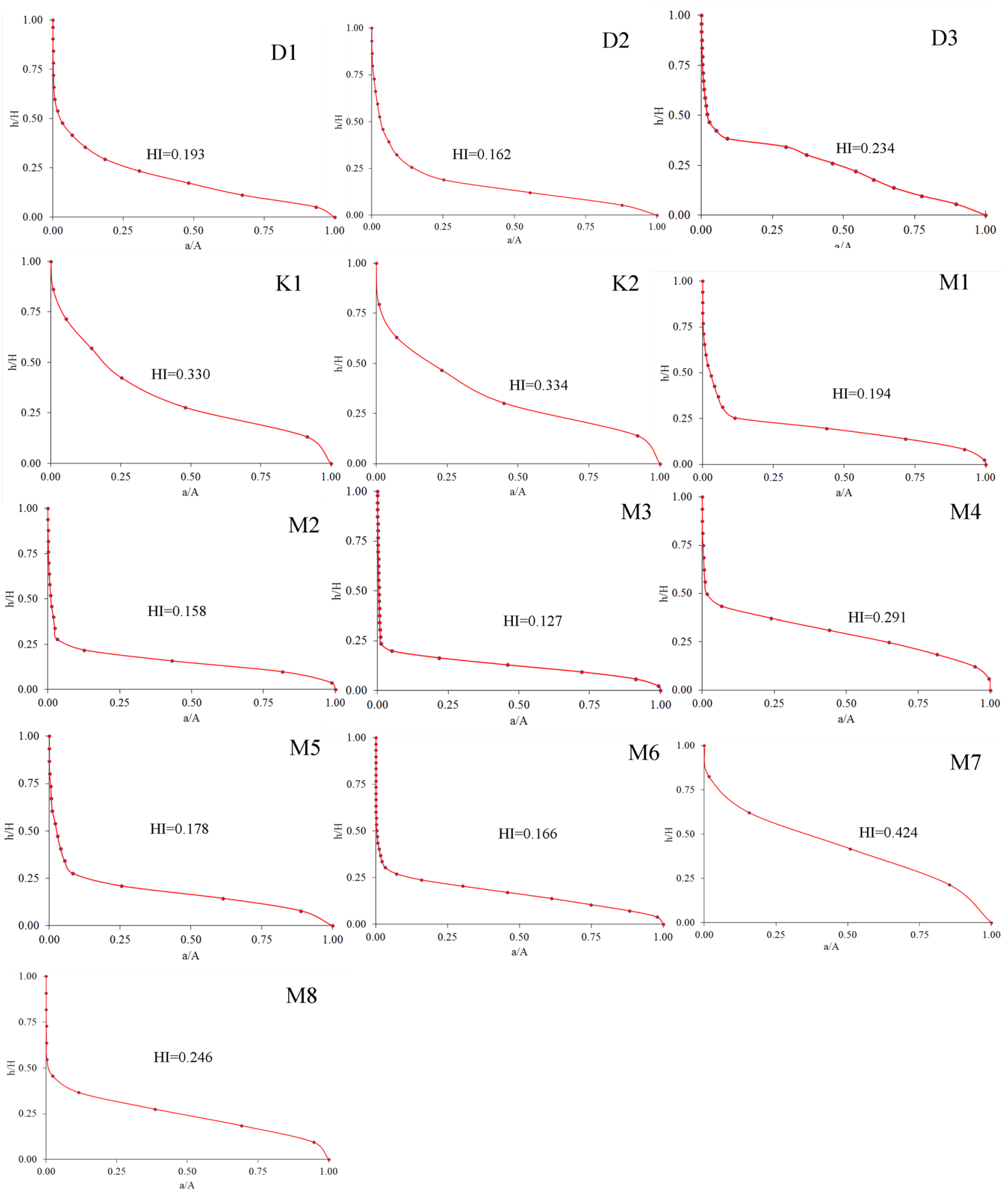

Fig. 8 Hypsometric curve of the tributary basins 
Table 5 Correlations matrix

\begin{tabular}{|c|c|c|c|c|c|c|c|c|c|c|c|c|c|c|c|}
\hline & $\mathrm{BM}$ & $\mathrm{BR}$ & DD & SF & DT & ER & CR & FF & CC & $\mathrm{RR}$ & DI & $\mathrm{RN}$ & AS & RT & $\mathrm{HI}$ \\
\hline $\mathrm{BM}$ & 1 & & & & & & & & & & & & & & \\
\hline $\mathrm{BR}$ & 0.189 & 1 & & & & & & & & & & & & & \\
\hline $\mathrm{DD}$ & $0.955^{* *}$ & $\quad 0.112$ & 1 & & & & & & & & & & & & \\
\hline SF & $0.992^{* *}$ & 0.108 & $0.975^{* *}$ & 1 & & & & & & & & & & & \\
\hline DT & $0.983^{* *}$ & 0.108 & $0.961^{* *}$ & $0.993^{* *}$ & * 1 & & & & & & & & & & \\
\hline ER & 0.423 & -0.264 & 0.505 & 0.467 & 0.431 & 1 & & & & & & & & & \\
\hline CR & 0.429 & -0.198 & $0.558^{*}$ & 0.498 & 0.485 & $0.653^{*}$ & 1 & & & & & & & & \\
\hline $\mathrm{FF}$ & 0.357 & -0.292 & 0.434 & 0.402 & 0.368 & $0.992^{* *}$ & $0.584^{*}$ & 1 & & & & & & & \\
\hline $\mathrm{CC}$ & -0.51 & 0.101 & $-.646^{*}$ & $-.572^{*}$ & -0.549 & $-.662^{*}$ & $-.966^{* *}$ & $-.583^{*}$ & 1 & & & & & & \\
\hline $\mathrm{RR}$ & $0.618^{*}$ & -0.284 & $0.619^{*}$ & $0.629^{*}$ & $0.644^{*}$ & 0.311 & 0.361 & 0.261 & -0.359 & 1 & & & & & \\
\hline DI & -0.269 & -0.079 & -0.352 & -0.332 & -0.331 & -0.287 & -0.373 & -0.295 & 0.392 & 0.371 & 1 & & & & \\
\hline $\mathrm{RN}$ & 0.49 & -0.231 & 0.488 & 0.486 & 0.498 & 0.184 & 0.214 & 0.136 & -0.221 & $0.972^{* *}$ & $0.557^{*}$ & 1 & & & \\
\hline AS & 0.538 & -0.419 & $0.660^{*}$ & $0.603^{*}$ & $0.567^{*}$ & 0.481 & $0.593^{*}$ & 0.424 & $-.583^{*}$ & 0.551 & -0.212 & 0.437 & 1 & & \\
\hline $\mathrm{RT}$ & $0.612^{*}$ & -0.524 & $0.680^{*}$ & $0.677^{*}$ & $0.661^{*}$ & $0.698^{* *}$ & $0.773^{* *}$ & $0.652^{*}$ & $-.722^{* *}$ & $0.564^{*}$ & -0.317 & 0.393 & $0.772^{* *}$ & 1 & \\
\hline $\mathrm{HI}$ & -0.432 & 0.55 & -0.433 & -0.454 & -0.432 & $-.606^{*}$ & -0.551 & $-.568^{*}$ & 0.483 & $-.751^{* *}$ & -0.276 & $-.687^{* *}$ & $-.585^{*}$ & $-.800^{* *}$ & 1 \\
\hline
\end{tabular}

Computed by the authors, 2018

**Correlation is significant at the 0.01 level at 2-tailed, ${ }^{*}$ Correlation is significant at the 0.05 level at 2-tailed

Table 6 Factor loading in PC-I and PC-II

\begin{tabular}{|c|c|c|c|c|c|c|c|c|}
\hline \multirow[t]{2}{*}{ Variables } & \multicolumn{2}{|c|}{ PC-I loadings } & \multicolumn{2}{|c|}{ PC -II loadings } & \multicolumn{2}{|c|}{ PC-I explained variation } & \multicolumn{2}{|c|}{ PC-II explained variation } \\
\hline & Initial & $\begin{array}{l}\text { Rotated (vari- } \\
\max \text { ) }\end{array}$ & Initial & $\begin{array}{l}\text { Rotated (vari- } \\
\max )\end{array}$ & Initial & $\begin{array}{l}\text { Rotated (vari- } \\
\max )\end{array}$ & Initial & $\begin{array}{l}\text { Rotated (vari- } \\
\max \text { ) }\end{array}$ \\
\hline BM & 0.828 & 0.785 & -0.076 & 0.275 & \multirow{15}{*}{$\begin{array}{l}53.956 \\
\qquad\left(\Sigma^{2}=8.093\right)\end{array}$} & \multirow{15}{*}{$\begin{array}{l}47.462 \\
\quad\left(\Sigma^{2}=7.119\right)\end{array}$} & \multirow{15}{*}{$\begin{array}{l}16.517 \\
\left(\Sigma^{2}=2.478\right)\end{array}$} & \multirow{15}{*}{$\begin{array}{l}23.011 \\
\quad\left(\Sigma^{2}=3.452\right)\end{array}$} \\
\hline $\mathrm{BR}$ & -0.24 & -0.069 & -0.36 & -0.427 & & & & \\
\hline $\mathrm{DD}$ & 0.887 & 0.865 & -0.14 & 0.243 & & & & \\
\hline SF & 0.872 & 0.837 & -0.106 & 0.266 & & & & \\
\hline DT & 0.855 & 0.815 & -0.091 & 0.273 & & & & \\
\hline ER & 0.73 & 0.761 & -0.234 & 0.092 & & & & \\
\hline $\mathrm{CR}$ & 0.764 & 0.808 & -0.273 & 0.07 & & & & \\
\hline $\mathrm{FF}$ & 0.666 & 0.705 & -0.24 & 0.059 & & & & \\
\hline $\mathrm{CC}$ & -0.782 & -0.844 & 0.319 & -0.036 & & & & \\
\hline $\mathrm{RR}$ & 0.727 & 0.395 & 0.637 & 0.882 & & & & \\
\hline $\mathrm{DI}$ & -0.245 & -0.594 & 0.892 & 0.709 & & & & \\
\hline $\mathrm{RN}$ & 0.576 & 0.205 & 0.766 & 0.936 & & & & \\
\hline AS & 0.779 & 0.683 & 0.06 & 0.379 & & & & \\
\hline $\mathrm{RT}$ & 0.903 & 0.833 & -0.03 & 0.349 & & & & \\
\hline $\mathrm{HI}$ & -0.749 & -0.484 & -0.472 & -0.741 & & & & \\
\hline
\end{tabular}

Computed by the authors, 2018 (Note the bold numerical figures indicate strong loadings)

portrays that most of the sub-basins belong to the old stage $(\mathrm{HI}<0.35)$ (Fig. 8). Thus, all the basins have attained steady-state equilibrium conditions in the evolutionary process. One of the important features is the presence of residual hills akin to monadnock [61]. 


\subsection{Association between morphometric parameters and their orientation to flood}

To glean out the perspective of association between the 15 morphometric variables we have performed bi-variate correlation (Table 5) that depicts a strong and significant

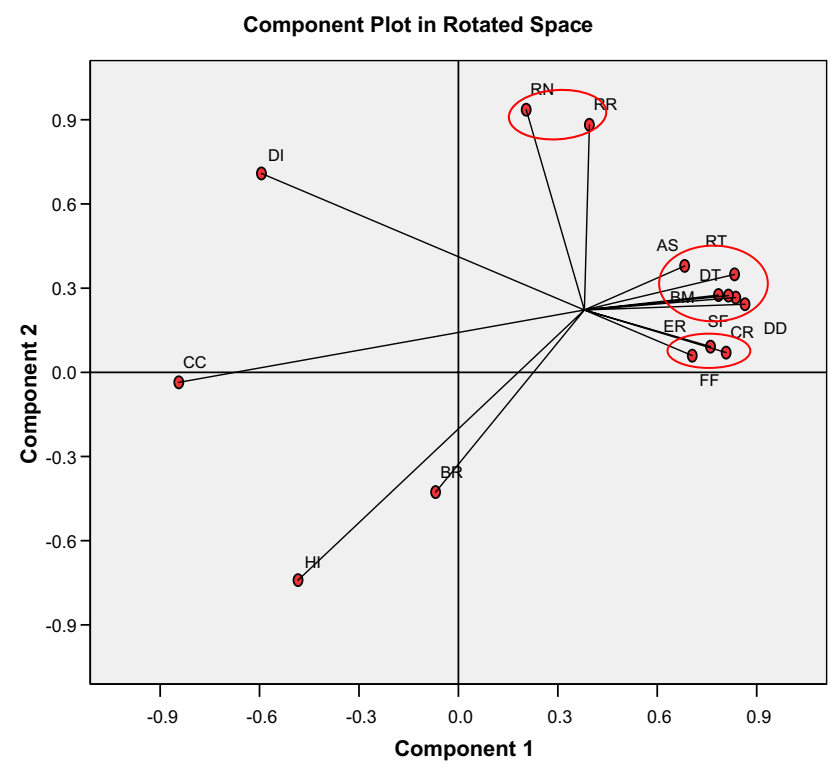

Fig. 9 Association of morphometric indices on 2-dimensional component plot correlation between some bi-variate couplings while others have had insignificant relations. The strong positive relations $(r>0.65)$ have been observed between RR-RN, RT-AS, BM-DD, BM-SF, BM-DT, RT-ER, RT-DT, RT-SF, RT-DD, RT-CR, RT-FF, DD-SF, DD-DT, SF-DT, ER-FF. The correlations are significant at the 0.01 level (2-tailed). Besides, moderately strong positive relations ( $r=0.55$ to 0.65 ) have been shown by the couplings of RR-BM, RR-RT, RR-DD, RR-SF, RR-DT, DI-RN, AS-SF, AS-CR, BM-RT, DD-CR, CR-FF. These are also significant at the 0.05 level (2 tailed). Similarly, there are few couplings HI-RT, HI-RR, HI-RN, RT-CC, CR-CC, ER-CC having strong negative correlations $(r \geq-0.65)$ and also portraying high significance level (0.01) at 2-tailed. Besides, we have found that some sets $\mathrm{HI}-\mathrm{AS}, \mathrm{HI}-\mathrm{FF}, \mathrm{HI}-\mathrm{ER}$, HI-CR, AS-CC, DD-CC, SF-CC, FF-CC have moderately strong negative relation $(r=-0.55$ to -0.65$)$. These relations are also significant at 0.05 level at 2 -tailed. Thus, we have found that RT is having the widest association with the other variables followed by AS and RR. However, the $\mathrm{RN}$ is distancing from the other neighbouring variables significantly.

Bi-variate correlation gives an impression of the two variables only. Thus, to depict the association between different variables on multi-dimensional space and to find out the main morphometric variables responsible for inducing flood we run a PCA. The initial factor loading in PC-I shows that the RT with the highest score (0.903) is controlling the system in a positive direction thereby inducing a

Table 7 Estimation of discharge, lag time and time of concentration

\begin{tabular}{|c|c|c|c|c|c|c|}
\hline Sub-basin & Basin area $\left(\mathrm{km}^{2}\right)$ & $\begin{array}{l}\text { Basin length } \\
(\mathrm{km})\end{array}$ & Slope $\left({ }^{\circ}\right)$ & $Q \max \left(825 A^{\wedge} 0.75\right)$ & Basin lag time $(\mathrm{h})$ & $\begin{array}{l}\text { Time of con- } \\
\text { centration (h) }\end{array}$ \\
\hline D1 & 557.07 & 42.48 & 1.51 & $94,599.32$ & 6.47 & 10.80 \\
\hline $\mathrm{D} 2$ & 272.66 & 27.86 & 1.54 & $55,357.04$ & 4.59 & 7.66 \\
\hline D3 & 1262.94 & 72.77 & 2.32 & $174,779.79$ & 8.06 & 13.46 \\
\hline $\mathrm{K} 1$ & 554.11 & 60.27 & 0.75 & $94,221.36$ & 10.78 & 18.00 \\
\hline $\mathrm{K} 2$ & 726.16 & 54.49 & 0.84 & $115,406.10$ & 9.52 & 15.90 \\
\hline M1 & 202.68 & 24.31 & 3.13 & $44,316.62$ & 2.98 & 4.97 \\
\hline M2 & 321.61 & 21.82 & 1.99 & $62,654.94$ & 3.30 & 5.51 \\
\hline M3 & 316.32 & 31.98 & 1.93 & $61,879.98$ & 4.52 & 7.56 \\
\hline M4 & 381.70 & 34.33 & 1.94 & $71,242.95$ & 4.78 & 7.99 \\
\hline M5 & 121.87 & 16.33 & 2.66 & $30,260.94$ & 2.35 & 3.93 \\
\hline M6 & 874.45 & 49.42 & 2.09 & $132,664.17$ & 6.12 & 10.22 \\
\hline M7 & 177.92 & 26.70 & 1.18 & $40,190.12$ & 4.64 & 7.76 \\
\hline M8 & 72.68 & 16.56 & 2.18 & $20,535.06$ & 2.50 & 4.18 \\
\hline
\end{tabular}

Computed by the authors, 2018 
flood peak. Similarly, other variables like RR, RN, AS, BM, $\mathrm{DD}, \mathrm{SF}, \mathrm{DT}, \mathrm{ER}, \mathrm{CR}$, and FF having scored above 0.5 (Table 6) also controls strongly to induce peak flood. However, some variables like $\mathrm{HI}, \mathrm{DI}, \mathrm{BR}$, and $\mathrm{CC}$ are controlling the system in a negative direction thereby producing sustained flow pattern in the basin. In PC-II, RR, DI, and RN having loading above 0.5 control the system in a positive direction. However, the factors loadings derived through rotation in Varimax with Kaiser Normalization portray that reduced number of variables (DI, AS, BM, RT, DD, SF, DT, ER, CR, FF, and $C C$ ) appeared in $\mathrm{PC}-\mathrm{I}$ with higher factor loadings $(>0.5)$ while an increasing number of variables ( $\mathrm{HI}, \mathrm{RR} \mathrm{DI}$ and $\mathrm{RN}$ ) appeared in PC-II with factor loadings above 0.5 (Table 6) after rotation. Thus, the variations explained are distributed between the PCs. We have also observed that explained variation has decreased from about $54 \%$ at initial to about $47 \%$ after rotation in PC-I. Contrarily, Eigenvalue $(\lambda)$ has increased from about $17 \%$ at initial to about $23 \%$ after rotation in PC-II. Thus, the varimax rotation has eased the problem of finding the major control factors for the flood of the MRB. Based on the factors loadings (after varimax rotation) of the first two components of the PCA, we have delineated three clusters of variables (Fig. 9). It is interesting to note that all three clusters are located in the positive-positive quadrant (++). The first cluster is consisting of RN and
RR while the second and largest cluster is formed by six variables like AS, RT, BM, DT, SF, and DD. Similarly, the third cluster is constituted by the three variables like $E R, C P$, and FF. Furthermore, four variables have formed outliers in the system of which one (DI) is located in the positive-negative $(+-)$ quadrant another three $(\mathrm{CC}, \mathrm{HI}$, and $\mathrm{BR})$ are located in the negative-negative (--) quadrant (Fig. 9). However, the plot of spikes on the centroid method depicts that gravity of the system components is located in the positive-positive quadrant thereby inducing a peak flow.

\subsection{Discharge, lag time and flood}

Estimation of discharge using morphometric parameters especially the drainage basin area is a long-held tradition in flood geomorphology. However, computing the constant $(c)$ and the exponent $(k)$ is a major task before the hydrologists which depends on regional setting, range of area and climatic regime $[62,63]$. The ' $k$ ' trends to decrease with increasing area and aridity and increase with the increasing number of variables. Thus, ' $k$ ' varies according to the regional factors. For example, Myers [64] in the USA has devised $k=0.5$ while Dickens' value for India (then Bengal province) was 0.75 which continues its use in flood hydrology [47]. Similarly ' $c$ ' also varies in different regions.
Fig. 10 Relation between basin lag and drainage basin area

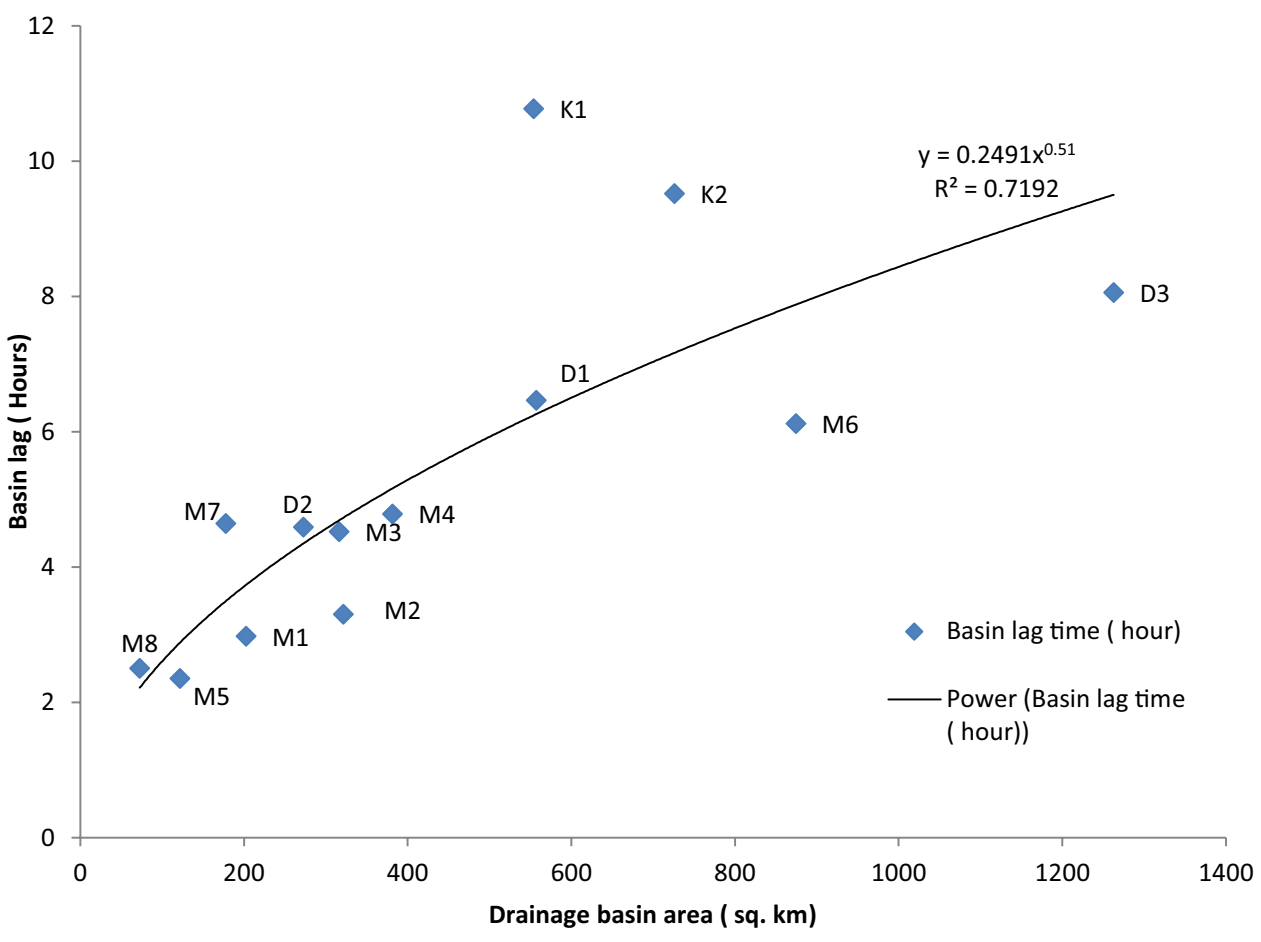


Table 8 Relationship between basin lag time (tL) and other morphometric properties

\begin{tabular}{|c|c|c|c|c|c|}
\hline \multirow{2}{*}{$\begin{array}{l}\text { Morpho- } \\
\text { metric } \\
\text { variables }\end{array}$} & \multicolumn{3}{|c|}{ Basin lag time } & \multirow{2}{*}{$\begin{array}{l}\text { Nature of } \\
\text { flow }\end{array}$} & \multirow{2}{*}{$\begin{array}{l}\text { Ranking } \\
\text { principle }\end{array}$} \\
\hline & $a$ & b & $r$ & & \\
\hline $\mathrm{BM}$ & 9.487 & -3.041 & $-.605^{*}$ & $\begin{array}{l}\text { Peak dis- } \\
\text { charge }\end{array}$ & 2 \\
\hline $\mathrm{BR}$ & 3.912 & 0.352 & 0.143 & $\begin{array}{l}\text { Sustained } \\
\text { flow }\end{array}$ & 1 \\
\hline $\mathrm{DD}$ & 12.531 & -4.675 & $-.726^{* *}$ & $\begin{array}{c}\text { Peak dis- } \\
\text { charge }\end{array}$ & 2 \\
\hline SF & 10.073 & -2.704 & $-.668^{*}$ & $\begin{array}{c}\text { Peak dis- } \\
\text { charge }\end{array}$ & 2 \\
\hline DT & 8.643 & -1.127 & $-.621^{*}$ & $\begin{array}{c}\text { Peak dis- } \\
\text { charge }\end{array}$ & 2 \\
\hline ER & 14.936 & -14.912 & $-.655^{*}$ & $\begin{array}{c}\text { Peak dis- } \\
\text { charge }\end{array}$ & 2 \\
\hline$C R$ & 13.163 & -24.743 & $-.790^{* *}$ & $\begin{array}{l}\text { Peak dis- } \\
\text { charge }\end{array}$ & 2 \\
\hline $\mathrm{FF}$ & 9.538 & -12.482 & $-.599^{*}$ & $\begin{array}{l}\text { Peak dis- } \\
\text { charge }\end{array}$ & 2 \\
\hline $\mathrm{CC}$ & -6.688 & 6.502 & $0.804^{* *}$ & $\begin{array}{l}\text { Sustained } \\
\text { flow }\end{array}$ & 1 \\
\hline $\mathrm{RR}$ & 6.467 & -0.003 & -0.191 & $\begin{array}{l}\text { Peak dis- } \\
\text { charge }\end{array}$ & 2 \\
\hline $\mathrm{DI}$ & -6.389 & 14.803 & $0.633^{*}$ & $\begin{array}{l}\text { Sustained } \\
\text { flow }\end{array}$ & 1 \\
\hline RN & 5.530 & -0.370 & -0.020 & $\begin{array}{c}\text { Peak dis- } \\
\text { charge }\end{array}$ & 2 \\
\hline AS & 10.449 & -2.709 & $-.697^{* *}$ & $\begin{array}{l}\text { Peak dis- } \\
\text { charge }\end{array}$ & 2 \\
\hline RT & 9.491 & -0.390 & $-.814^{* *}$ & $\begin{array}{l}\text { Peak dis- } \\
\text { charge }\end{array}$ & 2 \\
\hline $\mathrm{HI}$ & 2.385 & 13.047 & 0.430 & $\begin{array}{l}\text { Sustained } \\
\text { flow }\end{array}$ & 1 \\
\hline
\end{tabular}

** Correlation is significant at the 0.01 level (2-tailed).* Correlation is significant at the 0.05 level (2-tailed). a y intercept with $x$; b slope of the line; $r$ correlation coefficient; 1 higher rank for lower value of the variables; 2 higher rank for higher value of the variables

For example, in the Bengal area, it was computed to be 825. Thus, using this algorithm the maximum discharge has been computed for the sub-basins of the Mayurakshi River (Table 7). Similarly, we also have computed the other two significant variables of flood discharge-basin lag time and time of concentrations. We have observed that basin length is directly correlated with the basin lag and time of concentration and basin slope is inversely correlated with it. In the present study, we have found the sub-basin $\mathrm{K} 1$ has secured the highest ' $\mathrm{tL}$ ' of about $11 \mathrm{~h}$ and 'tc' of about $18 \mathrm{~h}$. On the other hand, sub-basin M5 is located at the bottom with ' $\mathrm{tL}$ ' of about $2.4 \mathrm{~h}$ and 'tc' about $4 \mathrm{~h}$ (Table 7). It can thus be argued that the higher the ' $\mathrm{LL}^{\prime}$ and ' $t c$ ', the lesser is the flow competence of the basin. This results in higher basin inundation and lesser capacity to induce flood in the lower stretch of the basin. Basin lag which thus determines the flood greatly is inversely correlated with rainfall intensity. However, the non-linearity in the relationship increases with the decreasing drainage density [65]. Boyd [66] established a geometric relation between stream orders and lag time like the equations of stream length [56] or stream area [33]. The higher the stream order, the higher is the basin lag. It is obvious that the higher the stream order, the higher is the basin area. Thus, lag time increases with the increasing basin area. For the Mayurakshi Basin, we have established a strong direct relation $\left(R^{2}=0.72\right)$ with an exponent of 0.51 (Fig. 10).

\subsection{Compound raking method and flood-inducing capacity index}

The compound ranking method is a common technique used widely by the geoscientists in the areas of rating statistics or order. However, rating the morphometric variables in the context of flood magnitude poses difficulty while assigning scaled values. For example, drainage density may increase the flood magnitude or decrease the flood magnitude depending upon the slope and other parameters of the basins. Thus, in the present context rating of 15 morphometric variables has been based on the empirical observation of the relation between basin lag and other morphometric variables (Table 8). This relation is assessed using the linear $(y c=a+b x)$ equation. The ' $a$ ' $(y$ intercept with $\mathrm{x}$ ), $\mathrm{b}$ (slope of the line) and ' $r$ ' (correlation coefficient) indicate the nature of relation (Table 8). If $r$ ' is positive between a chosen variable and lag time the flow will be of sustained nature. However, if it is negative flow will be portraying flood peak. Therefore we have followed the principle that the lower the rank scores the lower the lag time and higher efficiency for peak discharge and vice versa. Thus, following this principle we have ranked each of the 15 morphometric variables and summed up to get a compound rank. The un-weighted average ( $\mathrm{Cra}$ ) of this compound rank indicates the dynamics of the subbasin from the perspective of the morphometric indices (Table 9). Thus, we have observed that regarding Cra, M3 tops the list having a score of $\sim 10.5$ followed by the $M 1$ and $M 6$ both having a score of 9.13 (Table 9). Similarly, the rest of Mayurakshi sub-basins like the D1 (6.13), and D2 (6.53) induce flood moderately in the downstream portion 
Table 9 Morphometric coefficient, basin area coefficient and flood-inducing capacity index

\begin{tabular}{|c|c|c|c|c|c|c|c|c|}
\hline Sub-basin & $\begin{array}{l}\text { Compound } \\
\text { rank score } \\
(\mathrm{Cr})\end{array}$ & $\begin{array}{l}\text { Average com- } \\
\text { pound rank } \\
\text { (Cra) }\end{array}$ & $\begin{array}{l}\text { Drainage } \\
\text { basin area } \\
\left(\mathrm{km}^{2}\right)\end{array}$ & $\begin{array}{l}\text { Morphometric } \\
\text { coefficient (C) }\end{array}$ & $\begin{array}{l}\text { The ratio of } \\
\text { Basin area } \\
(\mathrm{a} / \mathrm{A})\end{array}$ & $\begin{array}{l}\text { Flood-induc- } \\
\text { ing capacity index } \\
\text { (FCl) }\end{array}$ & $\begin{array}{l}\text { The propor- } \\
\text { tion of } \mathrm{FCl} \\
(\%)\end{array}$ & $\mathrm{FCl}$ rank \\
\hline D1 & 92 & 6.13 & 557.07 & 0.0674 & 0.0954 & 0.0064 & 8.92 & 3 \\
\hline D2 & 98 & 6.53 & 272.66 & 0.0718 & 0.0467 & 0.0034 & 4.65 & 9 \\
\hline D3 & 91 & 6.07 & 1262.94 & 0.0667 & 0.2162 & 0.0144 & 19.99 & 2 \\
\hline K1 & 45 & 3 & 554.11 & 0.033 & 0.0948 & 0.0031 & 4.34 & 10 \\
\hline K2 & 49 & 3.27 & 726.16 & 0.0359 & 0.1243 & 0.0045 & 6.19 & 7 \\
\hline M1 & 137 & 9.13 & 202.68 & 0.1004 & 0.0347 & 0.0035 & 4.83 & 8 \\
\hline M2 & 133 & 8.87 & 321.61 & 0.0974 & 0.0551 & 0.0054 & 7.45 & 6 \\
\hline M3 & 157 & 10.47 & 316.32 & 0.115 & 0.0541 & 0.0062 & 8.63 & 4 \\
\hline M4 & 119 & 7.93 & 381.7 & 0.0872 & 0.0653 & 0.0057 & 7.9 & 5 \\
\hline M5 & 128 & 8.53 & 121.87 & 0.0938 & 0.0209 & 0.002 & 2.72 & 11 \\
\hline M6 & 137 & 9.13 & 874.45 & 0.1004 & 0.1497 & 0.015 & 20.84 & 1 \\
\hline M7 & 70 & 4.67 & 177.92 & 0.0513 & 0.0305 & 0.0016 & 2.17 & 12 \\
\hline M8 & 109 & 7.27 & 72.68 & 0.0799 & 0.0124 & 0.001 & 1.37 & 13 \\
\hline Total & & & 5842.17 & 1 & 1 & 0.0721 & 100 & \\
\hline
\end{tabular}

Note: Computed by the authors, 2018

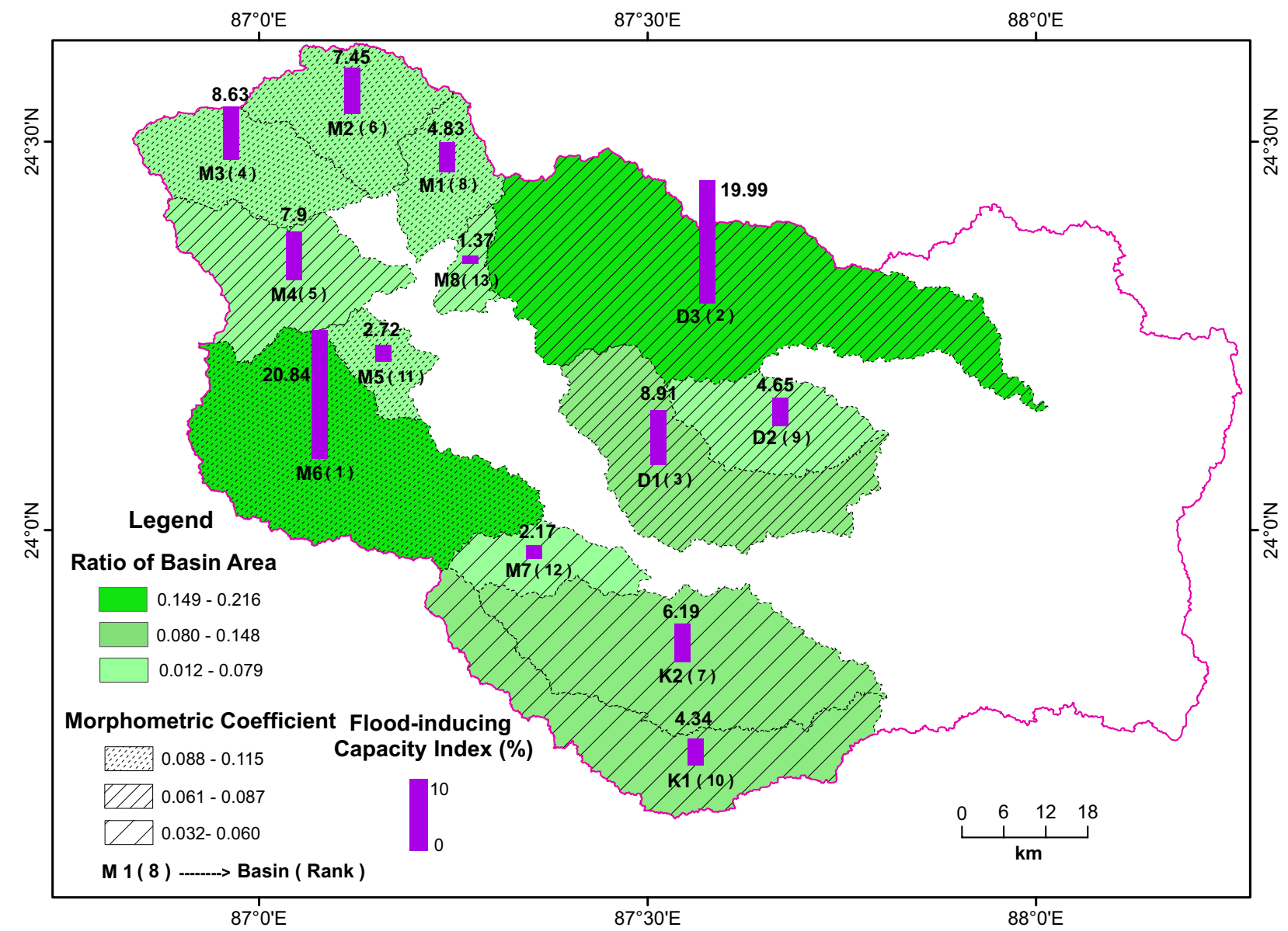

Fig. 11 Flood-inducing capacity of the tributary basins 
Table 10 Maximum discharge measured for the different subbasins during the monsoon

\begin{tabular}{lccc}
\hline Sub-basin & $\begin{array}{l}\text { Cross sectional area with reference to } \\
\text { wetted perimeter }\left(\mathrm{m}^{2}\right)\end{array}$ & Velocity $(\mathrm{m} / \mathrm{s})$ & $\begin{array}{l}\text { Maximum } \\
\text { Discharge } \\
\text { (Cumecs) }\end{array}$ \\
\hline D1 & 100.89 & 0.57 & 57.17 \\
D2 & 48.71 & 0.56 & 27.33 \\
D3 & 139.53 & 0.63 & 87.96 \\
K2 & 143.98 & 0.41 & 58.65 \\
M2 & 45.51 & 0.57 & 26.00 \\
M3 & 55.75 & 0.62 & 34.63 \\
M4 & 70.05 & 0.68 & 47.59 \\
M6 & 114.21 & 0.93 & 105.66 \\
M7 & 59.01 & 0.74 & 43.91 \\
\hline
\end{tabular}

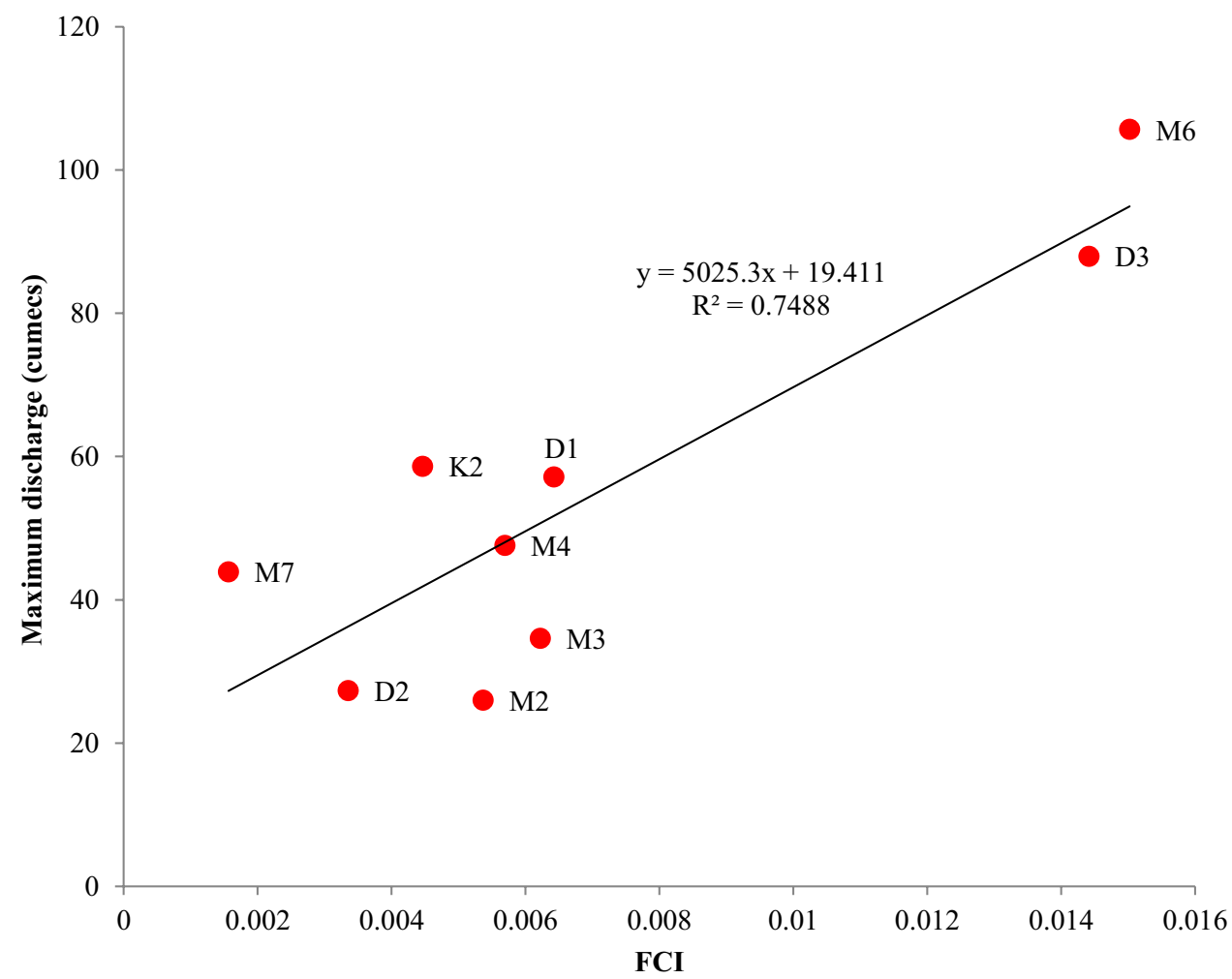

Fig. 12 Relation between the $\mathrm{FCl}$ and maximum discharge of the basin. The sub-basins D3 (6.07), and K2 (3.27) and K1 (3) determine the flood of the lower stretch of the basin with the minimum contribution in this scale. However, flood-inducing capacity greatly depends on the basin area. Thus, the ratio of basin area has been computed for every tributary basin which has been multiplied by the morphometric coefficients. Finally, we have derived the flood-inducing capacity index $(\mathrm{FCl})$ that portrays that $\mathrm{M} 6$ controls the flood of MRB with maximum efficiency while M8 with the least efficacy (Fig. 11).

\subsection{Validation}

The $\mathrm{FCl}$ has been validated with the maximum discharge $\left(Q_{M}\right)$ data measured from nine sub-basins. The highest $Q_{M}$ (105.66 cumecs) has been recorded for the M6 sub-basin while the lowest $Q_{M}$ (26 cumecs) has been portrayed by the M2 sub-basin (Table 10). It has been observed that there is a strong correlation $\left(R^{2}=0.75\right)$ between the $\mathrm{FCl}$ and the maximum discharge (Fig. 12). The student's $t$ test 


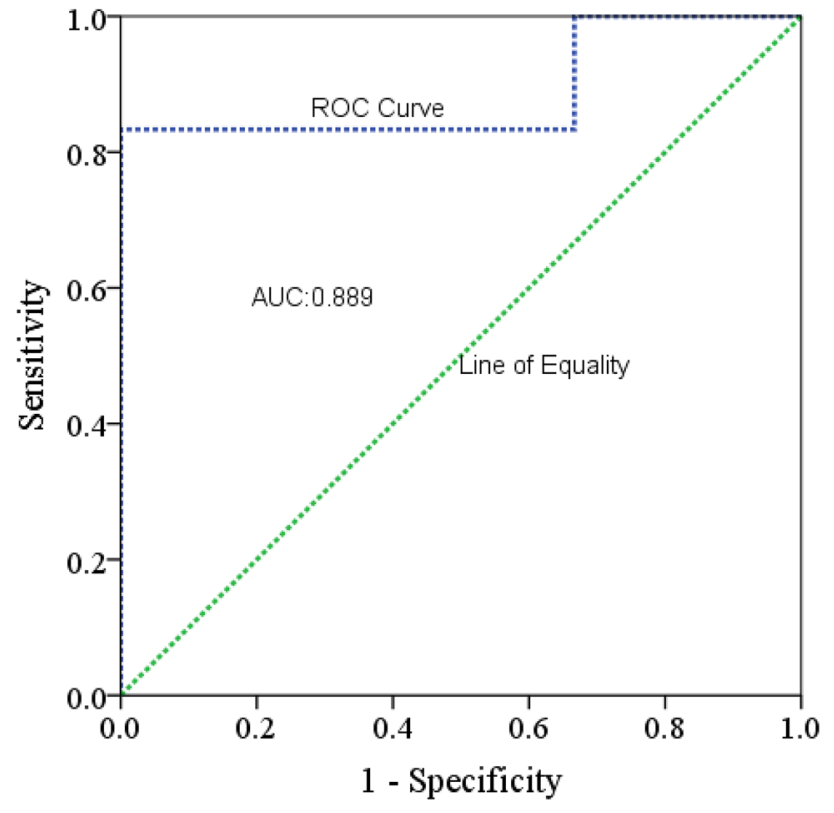

Fig. 13 Model validation using ROC curve

also portrays that the computed value of ' $t$ ' is 4.57 at $95 \%$ confidence level with 7 degrees of freedom $(v=n-2)$ while the tabulated ' $t$ ' value is 2.365 . This implies a statistically significant relation. Besides, the plot of the ROC curve (1-specificity versus sensitivity) shows that area under the curve (AUC) records 0.889 (Fig. 13). In other words, 88.9\% area falls under the ROC implying that the model is validated at a good category against $95 \%$ confidence level. This also proves that the proposed $\mathrm{FCl}$ is validated.

\section{Conclusion}

The annual nature of the flood of MRB is principally a response to the flashy nature of the rainfall regime of Chhotonagpur Plateau region. The PCA reveals that out of 15 morphometric indices five (RT, DD, SF, DT, and CR) having factor loading (after varimax rotation) $>0.8$ have emerged as the main factors controlling the flood magnitude. The bi-variate relations between the lag time and morphometric variables have segregated the four variables ( $\mathrm{HI}, \mathrm{DI}, \mathrm{CC}$, and $\mathrm{BR}$ ) promoting the sustained flow thereby reducing the peakedness in the discharge hydrograph. The compound ranking method involving the morphometric indices shows the morphometric coefficient $(C)$ of each of the 13 tributary river basins of MRB. Thus, the M3 has appeared as the principal basin having $C$ of 0.115 while sub-basin $\mathrm{K} 1(0.033)$ as the lowest contributing basin. Similarly, we also have derived basin area coefficient $(\mathrm{a} / \mathrm{A})$ being highest for $\mathrm{D} 3(0.216)$ and lowest for $\mathrm{M} 8$ (0.012). Finally, $\mathrm{FCl}$, a product of the $\mathrm{C}$ and $\mathrm{a} / \mathrm{A}$, has marked the $\mathrm{M} 6, \mathrm{D} 3, \mathrm{D} 1, \mathrm{M} 3, \mathrm{M} 4$, and $\mathrm{M} 2$ tributary basins (each having more than $7 \%$ contribution) as highly flood-inducing components of the MRB system. The correlation $\left(R^{2}=0.75\right)$ between the $\mathrm{FCl}$ and maximum discharge collected from the field measurements and the ROC (AUC $=0.889$ ) proves the suitability of the index to portray the role of the tributary basins to induce a flood of the master basin. However, as the index is purely based on the morphometric parameters this may be extended and tested in other climatic regions taking the consideration of factors like climate, vegetation, soil, and land use and land cover characteristics.

Acknowledgements The is paper is the outcome of the Major Research Project sponsored by the Indian Council of Social Science Research (ICSSR), Ministry of Human Resource Development (MHRD). Govt. of India vide the sanction order No. F.No.02/295/201617/ICSSR/ $\mathrm{RP}$ dated 29.03.2017. The first and the corresponding author (Al) working as the Project Director acknowledges the financial Grants of the ICSSR. Besides, the authors express their deep gratitude to Dr. Balai Chandra Das, Associate Professor in Geography, Krishnagar Government College, Nadia-741101, West Bengal, India for his sincere cooperation to develop the manuscript. Finally, this paper is dedicated to Al's mother.

\section{Compliance with ethical standards}

Conflict of interest On behalf of all authors, the corresponding author states that there is no conflict of interest.

\section{References}

1. Godschalk DR (1991) Disaster mitigation and hazard management. In: Drabek TE, Hoetmer GJ (eds) Emergency Management: principles and practice for local government. International City Management Association, Washington, DC, pp $131-160$

2. Sanyal J, Lu XX (2006) Gis-based flood hazard mapping at different administrative scales: a case study in gangetic West Bengal, India. Singapore J Trop Geogr 27(2006):207-220

3. Guchhait SK, Islam A, Ghosh S, Das BC, Maji NK (2016) Role of hydrological regime and floodplain sediments in channel instability of the Bhagirathi River, Ganga-Brahmaputra Delta, India. Phys Geogr 37(6):476-510

4. Parua PK (2003) Flood management in Ganga-BrahmaputraMeghna basin: some aspects of regional co-operation. Civil Engineering Today. ASCE-IS, Calcutta, pp 68-75

5. Ghosh S (2011) Hydrological changes and their impact on fluvial environment of the lower damodar basin over a period of fifty years of damming the mighty Damodar River in Eastern India. Procedia Soc Behav Sci 19:511-519

6. Nardi F, Morrison RR, Annis A, Grantham TE (2018) Hydrologic scaling for hydrogeomorphic floodplain mapping: insights into human-induced floodplain disconnectivity. River Res Appl 34(7):675-685

7. Leopold LB, Maddock T (1953) The hydraulic geometry of stream channels and some physiographic implications, vol 252. US Government Printing Office, Washington, D.C. 
8. Leopold LB, Miller JP (1956) Ephemeral Streams-Hydraulic Factors and Their Relation to the Drainage Net. U.S. Geol. Surv 282-A:1-37

9. Annis A, Nardi F, Morrison RR, Castelli F (2019) Investigating hydrogeomorphic floodplain mapping performance with varying DTM resolution and stream order. Hydrol Sci J 64(5):525-538

10. Jafarzadegan K, Merwade V (2017) A DEM-based approach for large-scale floodplain mapping in ungauged watersheds. J Hydrol 550:650-662

11. Samela C, Troy TJ, Manfreda S (2017) Geomorphic classifiers for flood-prone areas delineation for data-scarce environments. Adv Water Resour 102:13-28

12. Pal S et al (2012) Assessment of channel width disparity of the major rivers within Mayurakshi River Basin. Int Jeol Earth Environ Sci 2(3):1-10

13. Bhattacharya A (2013) Evolution of the hydro-geonomic characteristics of flood in the Mayurakshi river basin of eastern India. Unpublished Ph.D. thesis in Geography, Visva-Bharati University, India

14. Mollah S (2016) Assessment of flood vulnerability at village level for kandi block of Murshidabad District. West Bengal. Current Science 110(1):81-86

15. Mukhopadhyay S, Das P (2013) Channel deranging and its impact: a study on Mayurakshi-Kuya interfluve, Santal Pargana and Birbhum Districts, Jharkhand and West Bengal. J Indian Geomorphol 2:37-45

16. Jha VC, Bairagya H (2012) Floodplain planning based on statistical analysis of tilpara barrage discharge: a case study on Mayurakshi River Basin. Caminhos De Geografia 13(43):326-334

17. Mukhopadhyay S, Let S (2014) Changing Flood Intensity Zone of Dwarka River Basin in Eastern India. Trans. Inst Indian Geograph 36(1):123-132

18. Das P, Pal S (2012) Empirical data based flood zoning in Kuya River Basin. Int J Appl Res Stud 1(1):111-119

19. Ghosh et al (2015) Surface runoff and soil erosion dynamics: a case study on bakreshwar river basin, eastern India. Int Res J Earth Sci 3(7):11-22

20. Pal S (2016) Impact of Tilpara barrage on backwater reach of Kushkarni River: a tributary of Mayurakshi River. Environ Dev Sustain. https://doi.org/10.1007/s10668-016-9833-4

21. Pal S (2016) Impact of Massanjore Dam on Hydro-geomorphological Modification of Mayurakshi River, Eastern India. Environ Dev Sustain 18:921-944. https://doi.org/10.1007/s1066 8-015-9679-1

22. Ghosh KG, Pal S (2015) Impact of dam and barrage on flood trend of lower catchment of mayurakshi river basin, eastern India. European Water 50:3-23

23. Patton PC, Baker VR (1976) Morphometry and floods in small drainage basins subject to diverse hydrogeomorphic controls. Water Resour Res 12:941-952

24. Chaudhury AK (1966) On the meteorological conditions responsible for heavy rainfall in ajay catchment Area. Indian J Meteorol Geophys 17:127-132

25. O'Malley LSS (1914) Bengal District Gazetteers-Murshidabad. The Bengal Secretariat Book Depot, Calcutta

26. Office of the District Magistrate (2016) District Disaster Management Plan, Murshidabad District. Govt. of West Bengal, Kolkata

27. Office of the District Magistrate (2014) Flood preparedness and Management Plan, Murshidabad District. Govt. of West Bengal, Kolkata

28. O'Malley LSS (1910) Birbhum District Gazetteer. Bengal Secretariat Book Depot, Calcutta

29. Walsh JHT (ed) (1902) A History of Murshidabad District (Bengal): with biographies of some of its noted families. Jarrold
30. Islam A, Guchhait SK (2017) Search for social justice for the victims of erosion hazard along the banks of river Bhagirathi by hydraulic control: a case study of West Bengal, India. Environ Develop Sustain 19(2):433-459

31. Islam A, Guchhait SK (2017) Analysing the influence of Farakka Barrage Project on channel dynamics and meander geometry of Bhagirathi river of West Bengal, India. Arab J Geosci 10(11):245

32. Shreve RL (1967) Infinite topologically random channel networks. J Geol 77:397-414

33. Schumm SA (1956) Evolution of drainage systems and slopes in badlands at perth Amboy, New Jersey. Geoll Soc Am Bull 67:597-646

34. Horton RE (1932) Drainage basin characteristics. Trans Am Geophys Union 13:350-361

35. Patel DP, Gajjar CA, Srivastava PK (2013) Prioritization of Malesari mini-watersheds through morphometric analysis: a remote sensing and GIS perspective. Environ Earth Sci 69(8):2643-2656

36. Miller VC (1953) A quantitative geomorphic study of drainage basin characteristics in the Clinch mountain area. Technical Report 3, Department Of Geology, Columbia University

37. Gravelius H (1914) Flusskunde, Göschen'sche Verlagshandlung, Berlin

38. Smith KG (1950) Standards for grading texture of erosional topography. Am J Sci 248(9):655-668

39. Hadley RF, Schumm SA (1961) Sediment Sources and Drainage Basin Characteristics in upper Cheyenne River basin. Water Supply Paper 1531-B:137-196

40. Strahler AN (1958) Dimensional analysis applied to fluvial eroded landforms. Geol Soc Am Bull 69:279-300

41. Wentworth CK (1930) A simplified method of determining the average slope of land surfaces. Am J Sci 20:184-194

42. Strahler AN (1952) Hypsometric (area-altitude) analysis of erosional topography. Geol Soc Am Bull 63:1117-1142

43. Kirpich ZP (1940) Time of concentration of small agricultural watersheds. Civil Eng 10(6):362

44. Chow VT (1962) Hydrologic determination of waterway areas for the design of drainage structures in small drainage basins. Univ Illinois Eng Exp Station Bull 462:104

45. Kennedy RJ, Watt WE (1967) The relationship between lag time and the physical characteristics of drainage basins in Southern Ontario. Int Assoc Sci Hydrol 85:867-874

46. Natural Environment Research Council (1975) Flood studies report, Hydrological studies, vol I. NERC, London

47. Alexander GN (1972) Effect of catchment area on flood magnitude. J Hydrol 16(3):225-240

48. Watt WE, Chow KC (1985) A General expression for basin lag time. Can J Civ Eng 12:291-300

49. National Resource Conservation Service (1972) National engineering handbook. U.S. Department of Agriculture, Washington DC

50. Kaiser HF (1958) The varimax criterion for analytic rotation in factor analysis. Psychometrika 23:187-200

51. O'Brien PC (1984) Procedures for comparing samples with multiple endpoints. Biometrics 40(4):1079-1087

52. Corps $P(1990)$ Irrigation Reference Manual. Information Collection \& Exchange Washington $D C$

53. Rasyid AR, Bhandary NP, Yatabe R (2016) Performance of frequency ratio and logistic regression model in creating GIS based landslides susceptibility map at Lompobattang Mountain, Indonesia. Geoenviron Disasters 3(1):19

54. Blyth K, Rodda JC (1973) A steam length study. Water Resour Res 9:1454-1461 
55. Stall JB, Fok YS (1967) Discharge as related to system morphology. In Symposium on River Morphology. blnt. Assoc. Sci. Hydrol. Berlin, pp 224-235

56. Horton RE (1945) Erosional development of stream and their drainage basin: hydrogeological approach to quantitative morphology. Bull Geol Soc Am 56:275-370

57. Sherman LK (1932) The relation of hydrographs of runoff to size and character of drainage basin. Trans Am Geophys Union 13:332-339

58. Strahler AN (1964) Quantitative geomorphology of drainage basins and channel networks. In: Chow VT (ed) Handbook of applied hydrology. McGraw Hill Book Company, New York, pp 4-11

59. Melton MA (1957) An analysis of the relations among the elements of climate, surface properties and geomorphology. Department of Geology. Columbia University, New York

60. Patton PC (1988) Drainage Basin Morphometry and Floods. In: Baker VR, Kochel RC, Patton PC (eds) Flood geomorphology. Wiley, New York, pp 51-65

61. Chakrabarti B (1985) A geomorphological analysis of the Mayurakshi river basin, unpublished Ph.D. thesis. The University of Burdwan: India
62. Benson MA (1962) Factors influencing the occurrence of floods in a humid region of diverse terrain: US Geological Survey Water-Supply Paper 1580-B. Factors affecting the occurrence of floods in the Southwest: US Geological Survey Water-Supply Paper, 196

63. Cruff RW, Rantz SE (1965) A comparison of methods used in flood-frequency studies for coastal basins in California (No. 1580-E). US Department of the Interior, Geological Survey

64. Myers VA (1969) Floods and their computation. Proc of Leningrad Sym UNESCO/IASH

65. Parker RS (1977) Experimental study of drainage basin evolution and its hydrologic implications. Hydrol Pap. No. 90

66. Boyd MJ (1978) A storage-routing model relating drainage basin hydrology and geomorphology. Water Resour Res 14:921-928

Publisher's Note Springer Nature remains neutral with regard to jurisdictional claims in published maps and institutional affiliations. 